Linköping Studies in Science and Technology

Thesis No. 1873

\title{
Controlling the growth of nanoparticles produced in a high power pulsed plasma
}

\author{
Rickard Gunnarsson
}

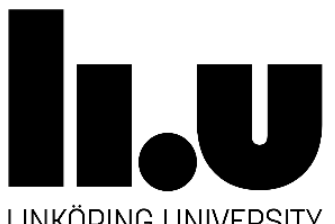

LINKÖPING UNIVERSITY

\author{
Plasma \& Coatings Physics Division \\ Department of Physics Chemistry and Biology \\ Linköping University, SE-581 83 Linköping, Sweden \\ Linköping 2017
}


(C) Rickard Gunnarsson, 2017

Printed in Sweden by LiU-Tryck

ISSN 0345-7524

ISBN 978-91-7685-466-2 


\section{Abstract}

Nanotechnology can profoundly benefit our health, environment and everyday life. In order to make this a reality, both technological and theoretical advancements of the nanomaterial synthesis methods are needed. A nanoparticle is one of the fundamental building blocks in nanotechnology and this thesis describes the control of the nucleation, growth and oxidation of titanium particles produced in a pulsed plasma. It will be shown that by controlling the process conditions both the composition (oxidation state) and size of the particles can be varied. The experimental results are supported by theoretical modeling.

If processing conditions are chosen which give a high temperature in the nanoparticle growth environment, oxygen was found to be necessary in order to nucleate the nanoparticles. The two reasons for this are 1: the lower vapor pressure of a titanium oxide cluster compared to a titanium cluster, meaning a lower probability of evaporation, and 2: the ability of a cluster to cool down by ejecting an oxygen atom when an oxygen molecule condenses on its surface. When the oxygen gas flow was slightly increased, the nanoparticle yield and oxidation state increased. A further increase caused a decrease in particle yield which is attributed to a slight oxidation of the cathode. By varying the oxygen flow, it was possible to control the oxidation state of the nanoparticles without fully oxidizing the cathode. Pure titanium nanoparticles could not be produced in a high vacuum system because oxygen containing gases such as residual water vapour have a profound influence on nanoparticle yield and composition. In an ultrahigh vacuum system titanium nanoparticles without significant oxygen contamination were produced by reducing the temperature of the growth environment and increasing the pressure of an argon-helium gas mixture within which the nanoparticles grew. The dimer formation rate necessary for this is only achievable at higher pressures. After a dimer has formed, it needs to grow by colliding with a titanium atom followed by cooling by collisions with multiple buffer gas atoms. The condensation event heats up the cluster to a temperature much higher than the gas temperature, where it is during a short time susceptible to evaporation. When the clusters' internal energy has decreased by collisions with the gas to less than the energy required to evaporate a titanium atom, it is temporarily stable until the next condensation event occurs. The temperature difference by which the cluster has to cool down before it is temporarily stable is exactly as many kelvins as the gas temperature. The addition of helium was found to decrease the temperature of the gas, making it possible for nanoparticles of pure titanium to grow. The process window where this is possible was determined and the results presented opens up new 
possibilities to synthesize particles with a controlled contamination level and deposition rate.

The size of the nanoparticles has been controlled by three means. The first is to change the electrical potential around the growth zone, which allows for size (diameter) control in the order of 25 to $75 \mathrm{~nm}$ without influencing the oxygen content of the particles. The second means is by increasing the pressure which decreases the ambipolar diffusion rate of the ions resulting in a higher growth material density. By doing this, the particle size can be increased from 50 to 250 $\mathrm{nm}$, however the oxygen content also increases with increasing pressure when this is done in a high vacuum system. The last means of size control was by adding a helium flow to the process where higher flows resulted in smaller nanoparticle sizes.

When changing the pressure in high vacuum, the morphology of the nanoparticles could be controlled. At low pressures, highly faceted near spherical particles were produced. Increasing the pressure caused the formation of cubic particles which appear to 'fracture' at higher pressures. At the highest pressure investigated, the particles became poly-crystalline with a cauliflower shape and this morphology was attributed to a low ad atom mobility.

The ability to control the size, morphology and composition of the nanoparticles determines the success of applying the process to manufacture devices. In related work presented in this thesis it is shown that 150-200 nm molybdenum particles with cauliflower morphology were found to scatter light, which made them useful in photovoltaic applications, and the size of titanium dioxide nanoparticles were found to influence the selectivity of graphene based gas sensors. 


\section{Populärvetenskaplig sammanfattning}

Idag är det lätt att se att vår värld förbättras av nanoteknologiska framsteg. När vi till exempel köper en ny telefon, märker vi att den är snabbare och kraftfullare än den vi köpte för två år sen. Om vi ska köpa en bil, så har vi möjligheten att välja en som drivs av elektricitet på grund av framstegen som görs i batteriutvecklingen. När vi köper ett hus så kan vi välja fönster som håller det kallt på sommaren och varmt på vintern. Framtiden kommer att erbjuda fler förbättringar och helt nya produkter som vi inte ens kan föreställa oss idag. Ett exempel på detta är en cancerterapi som skulle kunna både hitta och förgöra tumörer på en och samma behandling. För att nå dit, måste det ske en utveckling och en ökad förståelse av verktygen som används för att tillverka nanomaterialen. Denna avhandling fokuserar på en metod som tillverkar nanopartiklar, vilket är en av nanoteknologins grundläggande byggstenar. En nanopartikel är ett objekt med en storlek mindre än $100 \mathrm{~nm}$. Vad som gör dessa material speciella är att deras storlek påverkar deras egenskaper. Ett exempel på detta är när partiklarna i solkräm blir mindre, så absorberar de mer UV ljus men blir också transparanta för synligt ljus. Genom att finjustera deras storlek, form och materialsammansättning, så kan man skräddarsy partiklar med egenskaper som passar för de applikationer man vill använda dem i. Det finns många olika sätt att tillverka nanopartiklar på. En metod som alla kan testa hemma är att tända ett stearinljus och hålla en sked över lågan tills att den blir sotig. Sotet kommer då delvis att bestå av kolnanopartiklar. En annan metod som används är att mala ett bulkmaterial tills det uppnår en storlek mindre än $100 \mathrm{~nm}$. Dessa metoder är enkla att förstå, men saknar den kontrollen av partiklarnas egenskaper som ofta krävs. På en industriell skala tillverkas de ofta genom våtkemi, där kemikalier blandas i stora satser som bildar nanopartiklar. Detta orsakar dock problem med reproducerbarheten, eftersom det är svårt att få vätskan att blandas lika i varje sats. Ett annat problem är att spårämnen i vattnet kan kontaminera partiklarna, vilket kan orsaka problem om de ska användas som halvledare. Eftersom nanopartiklarnas egenskaper bestäms av deras storlek, form och samansättning så krävs det syntesmetoder som kan styra detta för att det ska gå att använda dem i de applikationer man tänkt sig.

Denna avhandling täcker syntes av nanopartiklar i ett pulsat plasma, där tillväxtmaterialet kommer från en titankatod. Genom at kollidera gasjoner med katodytan så kan man slå ut atomer från katodmaterialet. Denna process kallas för sputtring och atomerna som frigörs blandas med en gas som kyler utan att binda till dem. En stor andel av de sputtrade materialet tappar en elektron, vilket ger dem en positiv laddning. Denna positiva laddning hjälper till att attrahera andra atomer vilket är fördelaktigt när den blivande partikeln ska binda ihop sina två första atomer. När de binder ihop frigörs kemisk energi och värmer upp 
den nyskapta partikeln, därför måste de krocka med en tredje neutral gasatom för att kylas ner. Denna process kallas för 3-kropps kollisioner. Om det finns spårämnen av vatten kvar i gasfasen, så kan de första två atomerna som bildas genom en kollision mellan en titanatom och en vattenmolekyl. Vattenmolekylen kyls då av genom att frigöra en vätemolekyl och titanatomen binder till syreatomen. Sista delen av avhandlingen förklarar denna process och visar att titan bundet till syre kan växa i högre gastemperaturer än titan bundet till titan. Genom att sänka gastemperaturen var det då möjligt att skapa nanopartiklar av titan utan syrekontamination vilket är ett stort framsteg för de applikationer som kräver detta. Vill man istället göra oxiderade partiklar, så är det möjligt att med hög precision styra syrehalten genom att variera syrgasflödet in till processen. Det var även möjligt att styra storleken på nano partiklarna vid en valbar konstant syrehalt genom att ändra på potentialen mellan två anoder. Avhandlingen visar också att man kan styra storleken och strukturen på nanopartiklarna genom att variera trycket i zonen där de växer till.

Kunskapen som genererades under detta arbete fick även en praktisk användning i solceller och gassensorer. 


\section{Preface}

This thesis is part of my PhD studies in the Plasma \& Coatings Physics division of the department of Physics, Chemistry and Biology at Linköping University. The goal of my research is to study, control and understand the nucleation and growth of titanium nanoparticles synthesized in a novel pulsed plasma discharge. The results presented have partly been published in scientific journals and chapters in this thesis are based on my licentiate thesis Titanium oxide nanoparticle production using high power pulsed plasmas, Thesis No.1748 (2016) doi:10.3384/lic.diva-128622

This research primary financial support came from the Knut and Alice Wallenberg foundation. Financial support for the graphene based gas sensors came from The Centre in Nano science and technology (CeNano) 


\section{List of appended papers}

Paper 1 Synthesis of titanium-oxide nanoparticles with size and stoichiometry control

Rickard Gunnarsson, Ulf Helmersson, Iris Pilch

Journal of Nanoparticle Research 17, 1-11 (2015)

Paper 2 The influence of pressure and gas flow on size and morphology of titanium oxide nanoparticles synthesized by hollow cathode sputtering

Rickard Gunnarsson, Iris Pilch, Robert D. Boyd, Nils Brenning, Ulf Helmersson

Journal of Applied Physics 120, 044308 (2016)

Paper 3 Nucleation of titanium nanoparticles in an oxygenstarved environment, I: Experiments

Rickard Gunnarsson, Nils Brenning, Robert D. Boyd, Ulf Helmersson

Manuscript in preparation

Paper 4 Nucleation of titanium nanoparticles in an oxygenstarved environment, II: Theory

Rickard Gunnarsson, Nils Brenning, Lars Ojamäe, Michael Allan Raduu, Emil Kalered, Ulf Helmersson

Manuscript in preparation

The author's contribution to the appended papers

In paper $1 \mathrm{I}$ assembled the experimental setup, performed all of the experiments, characterized the nanoparticles with SEM and XRD and wrote a major part of the paper. 
In paper 2 I designed and constructed the new experimental setup, participated in planning the experiments, preformed all of the experiments, characterized the particles with SEM, prepared the first draft and wrote a major part of the paper

In paper 3 I designed and constructed the ultrahigh vacuum system, planned and performed the experiments, characterized the particles with SEM and XRD, developed the theory excluding the explanation for the process instability, prepared the first draft and wrote a major part of the paper

In paper $4 \mathrm{I}$ tied together the theory with previous experiments, modelled the dimer formation (excluding the quantum-chemical computations), helped develop the model for the nanoparticle heating and evaporation, and wrote parts of the paper. 


\section{Related Publications not included in this thesis}

Highly reflective rear surface passivation design for ultrathin $\mathrm{Cu}(\mathrm{In}, \mathrm{Ga}) \mathrm{Se}_{2}$ solar cells

Bart Vermang, Jörn TimoWätjen, Viktor Fjällströma, Fredrik Rostvall, Marika Edoff, Rickard Gunnarsson, Iris Pilch Ulf Helmersson, Ratan Kotipalli, Frederic Henry, Denis Flandre

Thin Solid Films, 582, 300-303 (2015) 


\section{Acknowledgements}

I would like to first thank Iris Pilch for supervising me from the time I was a bachelor's student to the time I got a licentiate degree. You have taught me the importance of not jumping to conclusions too early and how to conduct research with good ethics. I would like to thank Daniel Söderström for supervising me in the beginning of my Phd studies. You sparked my interest for vacuum and plasma technology. A later addition to my supervisors was Nils Brenning, who deserves a big thanks. You pushed me out of my comfort zone by making me do theoretical work, which I learned a lot from and this helped me develop as a scientist. Lastly, my main supervisor Ulf Helmersson deserves a huge thanks. You gave me freedom to pursue what I found important to work on and your enthusiasm to try new things will be an inspiration for my future career.

There are also other people that have helped me that deserve a big thank you. First Robert Boyd for his electron microscopy work on my particles. Daniel Magnfält who always had superb insights about the scientific problems that I was facing. Petter Larsson for all the equipment you have created which has come to great use throughout my research. Sebastian Ekeroth for the support and the fruitful discussions in the lab. Harri Savimäki who was always helpful, showing me tips and tricks in the workshop. Thomas Fransson for the scientific and not so scientific discussions. Therese Dannetun for your efficient and professional approach to solve bureaucratic issues.

Lastly thanks to past and present members of the plasma and coatings division, it was a pleasure working with all of you. 


\section{Table of contents}

Abstract .......................................................................................... ii

Populärvetenskaplig sammanfattning ............................................... V

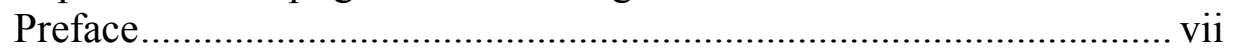

List of appended papers .......................................................... ix

Related Publications not included in this thesis................................... xi

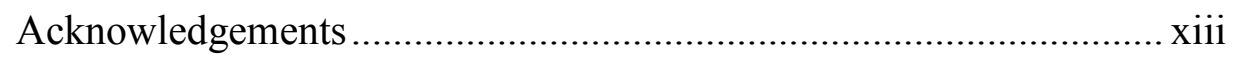

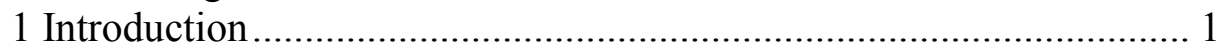

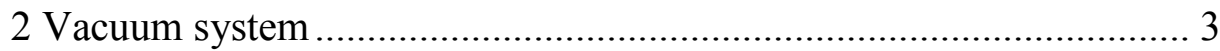

2.1 Pumps and pressure............................................................... 3

2.2 Flow regimes, diffusion and vapor pressure .............................. 5

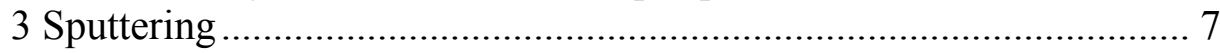

3.1 Non-reactive sputtering ..................................................... 7

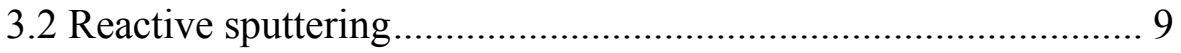

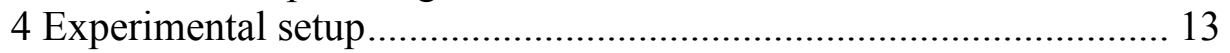

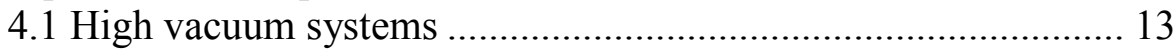

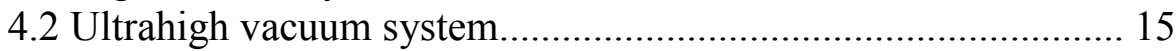

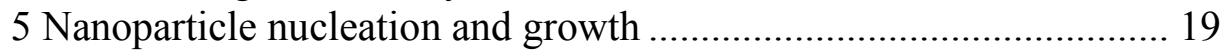

5.1 The creation of the first dimer.................................................... 19

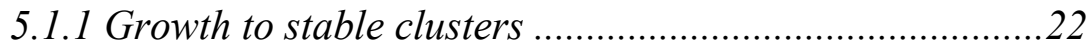

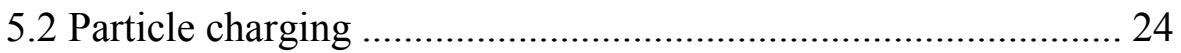

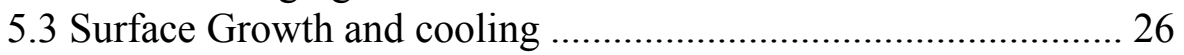

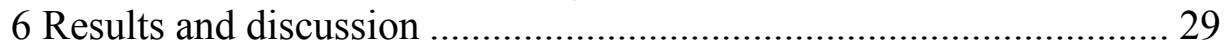

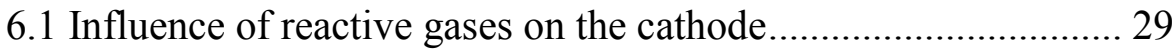

6.2 Size control ............................................................................ 32

6.2.1 Size control by changing the mesh bias ...........................32

6.2.2 Size control by pressure and gas flow............................... 34

6.3 Influence of reactive gases on the nanoparticles........................ 40

6.3.1 Influence on oxygen content and crystal structure...........40

6.3.2 Oxygens influence on the particle size ...........................43

6.3.3 The problems caused by residual gases ..........................44

6.4 The growth of nanoparticles without oxygen ........................... 48

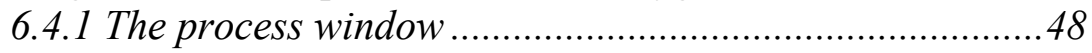

6.4.2 Nucleation model...........................................................50

6.4.2 The experimental parameters influence on the growth

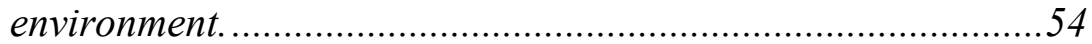

6.6 applying the process to manufacture devices............................. 56

6.6.1 Solar cells with molybdenum particles............................56 
6.6.2 Graphene based gas sensors.

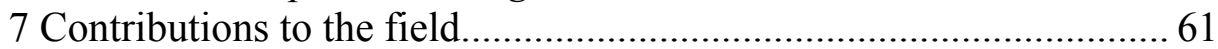

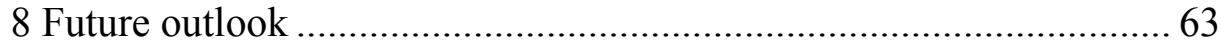

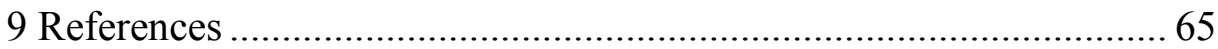




\section{Introduction}

Nanoparticles are one of the fundamental building blocks in nanotechnology which have the potential of greatly improving our life, health and environment. The reason they are of such big interest compared to bulk materials is that their properties often depend on their size. For instance, a sunscreen that is based on titanium dioxide will have an increased protection against UV rays if the particle size is decreased [1]. One other size-dependent property is their surface area to volume ratio. Ten grams of $2 \mathrm{~mm}$ titanium dioxide particles will have an area of $71 \mathrm{~cm}^{2}$, while ten grams of $2 \mathrm{~nm}$ particles will have an area of $7100 \mathrm{~m}^{2}$ which is the size of a football field. A high surface area is important for gas sensing and catalytic applications [2]. In addition to this, nanoparticles exhibit properties such as plasmonic resonances, which can enhance the efficiency of solar cells [3]. Nanoparticles are also dispersible in liquids and biological systems, which opens up doors for new diagnostics and treatments of cancer [4].

How well the nanoparticles perform in these applications depends generally on their size, shape, composition and the amount of particles that are being used. It is therefore crucial to have a nanoparticle synthesis process that allows for precise control over these properties. There are several ways of synthesizing nanoparticles. One easy way that anyone can do at home is to light a candle and hold a spoon close to the flame. The black soot that forms on the spoon will contain carbon nanoparticles [5]. One other method is to take a bulk object, and crush it into smaller pieces until it becomes nano-sized. These two methods are both simple and cheap, but they lack the required process control over the particle properties for them to be used in more sophisticated applications. On an industrial scale, wet chemistry is often used to produce nanoparticles. This is done by mixing a solution in a big batch where the nanoparticles nucleate and grow. Due to the complicated nature of mixing large batches, it is often challenging to control the size of the particles by this method [6]. In addition to this, if semiconductor grade particles are to be synthesized it is difficult to obtain a pure enough liquid media that do not contaminate the particles [7]. In this thesis a plasma-based synthesis method is used to grow nanoparticles. This process has previously shown promising results for nanoparticle size control [8] and fast nanoparticle growth [9]. However, it is still in its early stages of development and thus, fundamental understanding over the nucleation and growth process and what parameters influences the nanoparticle properties is not yet fully explored. In addition to this, previous research on this process had only been published on copper nanoparticles. The use of a more reactive material such as titanium in an oxygen containing environment poses new challenges to the synthesis method. This thesis covers the influence of oxygen 
on nanoparticles synthesized in a titanium plasma. It is shown that oxygen is under certain conditions necessary for the nanoparticles to nucleate, however it also causes problems with the process and the nanoparticle purity. The thesis will show how to circumvent this problem by changing the process to allow for nanoparticle growth without oxygen. It also covers the influence of pressure, gas flow and electrical potentials on the resulting nanoparticle size.

In order to explain the results of this work, it is important to understand every parameter of the process that has been found to influence the particles. These topics has been divided up in to: vacuum system, sputtering and nanoparticle growth. Since it was found that residual gases present in the process had a profound influence on the nucleation of the particles and oxidation of the cathode which is the source of growth material, the topic of vacuum systems will be discussed first. Then the process of sputtering will be introduced and how this residual water and other oxygen containing gases influences it. After this the experimental setups built for this work will then be presented followed by a theoretical introduction of the nanoparticle growth stages. To give a broader overview, the results in the papers are then presented together with some of the un-published results. Lastly two examples of how the process can be applied to manufacture devices will be given. 


\section{Vacuum system}

The plasma based nanoparticle synthesis process is operated inside a vacuum system. This section covers the different vacuum and flow regimes, what residual gases are and how it is possible to reduce their partial pressure.

\subsection{Pumps and pressure}

Vacuum is a space where gas has been removed so that the pressure is reduced compared to the atmospheric pressure. It is however not possible to remove all gas molecules from an enclosed volume to create a perfect vacuum. Instead different degrees of vacuum is often used to define how low pressure that is achieved.

Table 1: Different vacuum regimes

\begin{tabular}{|l|l|}
\hline Degree of Vacuum & Pressure range $(\mathrm{Pa})$ \\
\hline Low & $10^{5}>p>3.3 \cdot 10^{3}$ \\
\hline Medium & $3.3 \cdot 10^{3} \geq p>10^{-1}$ \\
\hline High & $10^{-1} \geq p>10^{-4}$ \\
\hline Very high & $10^{-4} \geq p>10^{-7}$ \\
\hline Ultrahigh & $10^{-7} \geq p>10^{-10}$ \\
\hline Extreme ultrahigh & $10^{-10}>p$ \\
\hline
\end{tabular}

In Table 1, the different vacuum regimes that will be discussed in this thesis are presented. The experimental setup used for paper 1 and paper 2 had a fluctuating base pressure in the border between high and very high vacuum. Both these regimes will from here on simply be referred to as "high vacuum". The lower the pressure is, the higher the vacuum is said to be. There are several factors that determine the lowest pressure that is possible to obtain. One factor is the type of pumps that are used. A positive displacement pump operate in the same way as a bicycle pump. As you pull the pump piston, the volume inside the pump increases which causes a pressure difference that makes air flow to fill this new volume. Then the gas is compressed and ejected to fill a bicycle tire and a new stroke of the piston repeats the cycle. In this analogy, the pressure in the room will decrease as the pressure in the tire increases. If this principle of pumping is used, no higher regimes than medium vacuum can be obtained. The reason for this is as the amount of gas atoms in the volume become less, they will collide with each other less frequently. Instead collisions with the wall of 
the vacuum system becomes more prominent. Since the atoms collide with the walls instead of with each other, a positive displacement volume will not be noticed, i.e. the atoms will not push each other to fill this volume. In addition to this, there will be back streaming of gas from the pump that will contribute to the pressure inside the chamber. This low efficiency of positive displacement pumps at low pressure leads to that a second pump has to be added. Today, turbomolecular pumps are often put before the positive displacement pumps in order to compress the gas to a regime where the positive displacement pump can operate. With this setup it is possible to reach ultrahigh vacuum [10].

A turbomolecular pump backed with a positive displacement pump are commonly used in high vacuum systems. But ultrahigh vacuum is not reached. The main reason for this is that the vacuum system has to be opened on a regular basis to change the substrates. This does not give the vacuum system enough time to pump away the residual water adsorbed on the chamber wall. One other contributing factor is that the chamber is sealed with rubber gaskets which gases such as oxygen, nitrogen and water vapor have a relatively high permeation rate through. The contribution of these gases minus the gases removed by the pump, gives rise to the so called base pressure [10]. In the high vacuum systems used in this thesis, a base pressure in the order of $10^{-4}-10^{-5} \mathrm{~Pa}$ is obtained. The dominating gas that gives rise to this pressure is water vapor.

Water vapor is a common problem in vacuum technology and there are several techniques that can be used to decrease its contribution to the base pressure. One method is to heat up the vacuum chamber, commonly referred to as baking. This increases the desorption rate of the water and initially increases the pressure of the system. When all water has desorbed, the pressure decreases to a lower level than before the baking procedure. Baking is however not as efficient on systems that have to be regularly opened and that are sealed with rubber gaskets. This is because the required baking time increases with decreasing temperature, and rubber gaskets are sensitive to high temperatures. One other technique to decrease the water vapor is to deposit a reactive coating inside the vacuum chamber. The desorbing water will land on this coating and bind to it which removes its contribution to the pressure [10]. This reactive coating is often titanium, which is also the material studied to make nanoparticles of in this thesis. Since titanium is highly reactive, the nanoparticle synthesis process will act as a pump that consumes water and binds it in to the particles and stray titanium coatings on the chamber wall.

To get rid of the large contribution of the water vapor and the problems associated with it, an ultrahigh vacuum system was built for paper 3. Pressures lower than $10^{-7} \mathrm{~Pa}$ was possible to achieve by several means. By using gaskets made of copper instead of rubber, the permeation was decreased and higher 
baking temperatures were allowed. The substrate table was also separated with a gate valve, which removed the need of opening the system after every experiment.

\subsection{Flow regimes, diffusion and vapor pressure}

The nanoparticle synthesis process cannot operate at the high vacuum regime because sputtering cannot be ignited [11] and particle nucleation does not occur at pressures of this low value. Because of this, argon gas is continuously flown through the system at a reduced pumping speed to increase the pressure. The total pressure of the system is given by the sum of the partial pressure of water, argon and other possible gases such as nitrogen, hydrogen and carbon dioxide. There are different flow regimes whose behavior depends on the pressure. The underlying reason for this pressure dependence is that the mean free path of the molecules depends on the gas density. Equation (1) shows how the mean free path $\lambda$ is calculated.

$$
\lambda=\frac{1}{2^{1 / 2} \pi d_{0}^{2} \mathrm{n}_{\mathrm{g}}}
$$

Here $d_{0}$ is the molecular diameter and $\mathrm{n}_{\mathrm{g}}$ is the gas density in molecules per cubic meter. The flow regime is defined by the Knudsen number $K n$, which is the ratio between the mean free path and the diameter of the pipe $d_{\mathrm{p}}$ that the gas flows through.

$$
K n=\frac{\lambda}{d_{\mathrm{p}}}
$$

When $K n>1$ the flow is said to be molecular. This means that the pipe diameter is smaller than the mean free path and the gases collide with the pipe wall instead of with other gas molecules. This is the regime previously discussed, where positive displacements pumps do not work. In the region of $\mathrm{Kn}<0.01$ the flow is said to be viscous or continuous. This means that the collisions between gas molecules are more frequent than collisions with the wall and it is in this regime that the nanoparticle synthesis process operate in [10].

Even thou there are collisions between gas molecules, the gas density is significantly lower than at atmospheric pressures. This leads to that gas diffusion becomes a significant factor to consider when reactive gases is introduced to the 
process. The diffusion coefficient of a gas within another gas with atoms of different size and mass can be expressed by

$$
D=\frac{2}{3} \sqrt{\frac{k_{\mathrm{B}}^{3}}{\pi^{3}}} \sqrt{\frac{1}{2 m_{1}}+\frac{1}{2 m_{2}}} \frac{4 T_{\mathrm{g}}{ }^{3 / 2}}{p\left(d_{1}+d_{2}\right)^{2}}
$$

Where $T_{\mathrm{g}}$ is the gas temperature in Kelvin, $m_{1}$ and $m_{2}$ is the two different gas molecules mass, $p$ is the pressure $d_{1}$ and $d_{2}$ is the collision diameter of the two different gases and $k_{\mathrm{B}}$ is the Bolzmann constant [12]. For a pressure of $110 \mathrm{~Pa}$ and a temperature of $300 \mathrm{~K}$, the diffusion coefficient of oxygen in argon becomes $0.01 \mathrm{~m}^{2} / \mathrm{s}$, which is low enough that the inert gas flow of argon could be used to prevent oxidation of the cathode.

Another aspect within a vacuum system that has to be considered is the different materials vapor pressure. Simply put a material with a high vapor pressure will evaporate quicker than a material with a low vapor pressure. The vapor pressure has a very strong temperature dependence, given by

$$
p_{\text {vap }}=10^{A-\frac{B}{T}}
$$

Where A and B are element specific constants [13]. Hot gases within the experimental setup were found to evaporate the growing nanoparticles quicker in paper 3 and paper 4 , preventing them to form.

In summary, the process environment starts off in a high or ultrahigh vacuum state. The degree of vacuum determines how much contaminants that are present in the process. Then argon is continuously flown at a decreased pumping speed to increase the pressure. At the higher pressure, the argon gas can be used as a shielding gas to reduce the flux of water vapor counter to the flow. The following section will cover how the growth material gets ejected from the cathode and how it interacts with the surrounding gas. 


\section{Sputtering}

\subsection{Non-reactive sputtering}

Sputtering is when a particle with mass such as an ion collides with a surface of a material and due to the collision, atoms from the material is ejected. The material can be either liquid or solid and is often referred to as a target [14]. The underlying mechanism behind the ejection of the sputtered material from a solid surface depend on the size of the ions used. Heavy ions colliding with the surface causes a cascade of collisions between target atoms. As the collision cascade develops, some of the collisions will be directed towards the cathode surface, which will knock out atoms. If a light ion is used instead of a heavy ion, sputtering will not occur from collisions with the surface. Instead the ion will first collide deeper inside the cathode material, and then strike out the surface material from the backside. For ions of intermediate size, such as argon, both mechanisms contribute to the amount of sputtered material [15]. The sputter yield is defined as the number of ejected target atoms per incoming ion [16]. This value depends on the angle, mass and kinetic energy of the incoming ion as well as what target material that is being used [15]. It is not only atoms that gets ejected from the surface during sputtering, secondary electrons are also released as the ions approaches the cathode surface. If these secondary electrons get accelerated by the negative potential of the cathode, they will obtain enough kinetic energy to further ionize the argon gas close to the cathode and this ionization process creates a plasma [17].
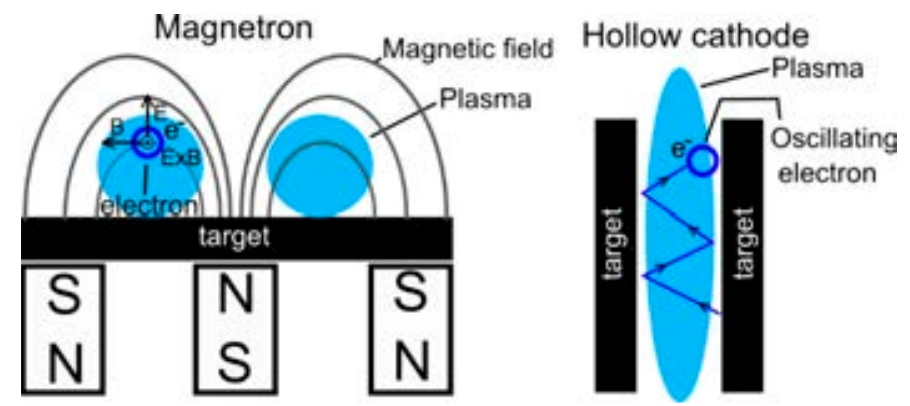

Figure 1: The different mechanisms for confining electrons in a magnetron and a hollow cathode

When using sputtering to synthesize nanoparticles, it is common to use a magnetron in a gas aggregation cluster source based on the Haberland concept 
[18]. A sputter magnetron is device where a magnetic field is present in the vicinity to the target surface. An illustration of a magnetron can be found in Figure 1. The purpose of the magnetic field is to confine the secondary electrons close to the target surface. The electrons will first be accelerated by the electric field. Then as the magnetic field becomes parallel with the cathode surface, their trajectory will bend towards the surface where they might be reflected again. This causes a hopping motion of the electrons where ionizing collisions with neutral atoms can occur [19]. This will locally increase the plasma density and since more ions are available, it helps to sustain the discharge at lower pressures [20]. However, a magnetron is not used in the present work, instead a hollow cathode is utilized. The hollow cathode is in this case a cylinder, where the discharge develops inside. The electron trapping inside a hollow cathode occurs by a different means than that of a magnetron. When high energy electrons gets released from the cathode surface it will first be accelerated by the cathode sheath and the repelled by the cathode sheath on the opposite side. This causes an oscillation of the electrons inside the hollow cathode. Collisions with these electrons will ionize the gas atoms, which results in a highly ionized plasma [21].

To further increase the ionization of the plasma, high powered electrical pulses has been used. This is done by applying square wave voltage pulses of a higher amplitude than would have been possible in direct current (DC) mode without melting the target [17].

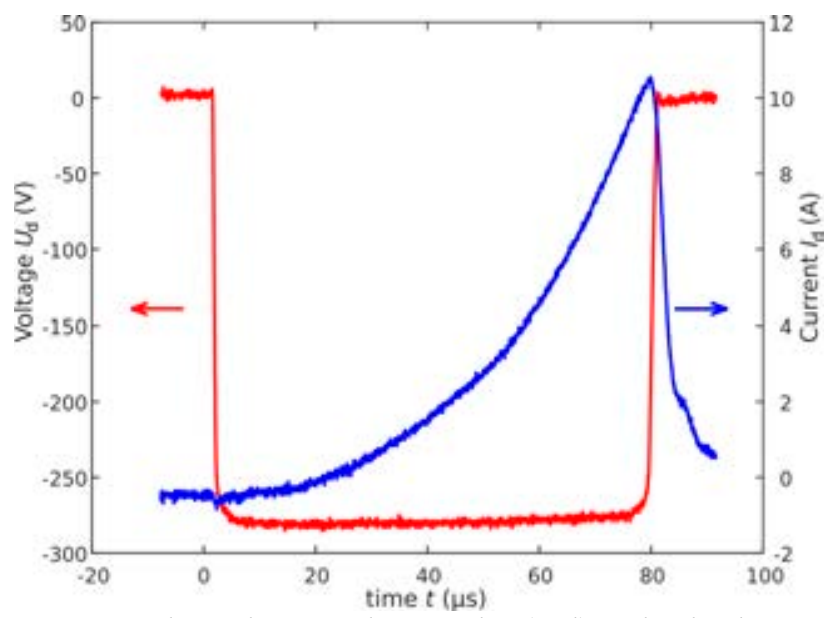

Figure 2: A typical Discharge voltage pulse (red) and a discharge current curve (blue)

In Figure 2, a typical discharge voltage (red) and current (blue) is shown during one pulse of $80 \mu \mathrm{s}$. Pulsed voltages and peak currents in the order of $280 \mathrm{~V}$ and 
10 A can be reached at a frequency of $1500 \mathrm{~Hz}$ without damaging the experimental setup.

Due to the confined geometry of the hollow cathode, most of the sputtered material will not be ejected out from it. Instead most of the material will get re deposited on the cathode surface. The use of voltage pulses to initiate sputtering, results in a pulsed ejection of the sputtered material [17]. The behavior is similar to the ejection puffs of smoke from a person smoking a cigar. To estimate the amount of ions ejected in each puff, the following relationship can be used.

$$
N_{\text {pulse }}=\frac{\int\left(I_{\text {pulse }}\right) d t Y_{\text {sput }} \Gamma_{\mathrm{M}, \text { exit }} \Gamma_{\text {ions }}}{e}
$$

Where $\int\left(I_{\text {pulse }}\right) d t$ is the amount of amperes per pulse (the area beneath the blue curve in figure 2), $Y_{\text {sput }}$ is the sputter yield, $\Gamma_{\mathrm{M} \text {,exit }}$ is the average fraction of the sputtered ions that gets extracted during the first $150 \mu$ s from pulse start and $\Gamma_{\text {ions }}$ is the fraction of this material that is ionized. The constant $e$ is the elementary charge. If the same values for extraction efficiency and ionization as calculated for aluminium [17] is used, we get that each pulse ejects approximately $8 \cdot 10^{13}$ ions and $4 \cdot 10^{12}$ neutrals.

\subsection{Reactive sputtering}

When a reactive gas that can chemically bind to the sputtered material is added, the process becomes a reactive sputtering process. A complex interplay between the inflow of reactive gas, oxidation of the cathode, reaction with the deposited material and the pumping speed of the vacuum chamber arises. The process can be characterized and understood by flowing oxygen to the process and monitoring its partial pressure. A so called hysteresis curve is then often plotted. 


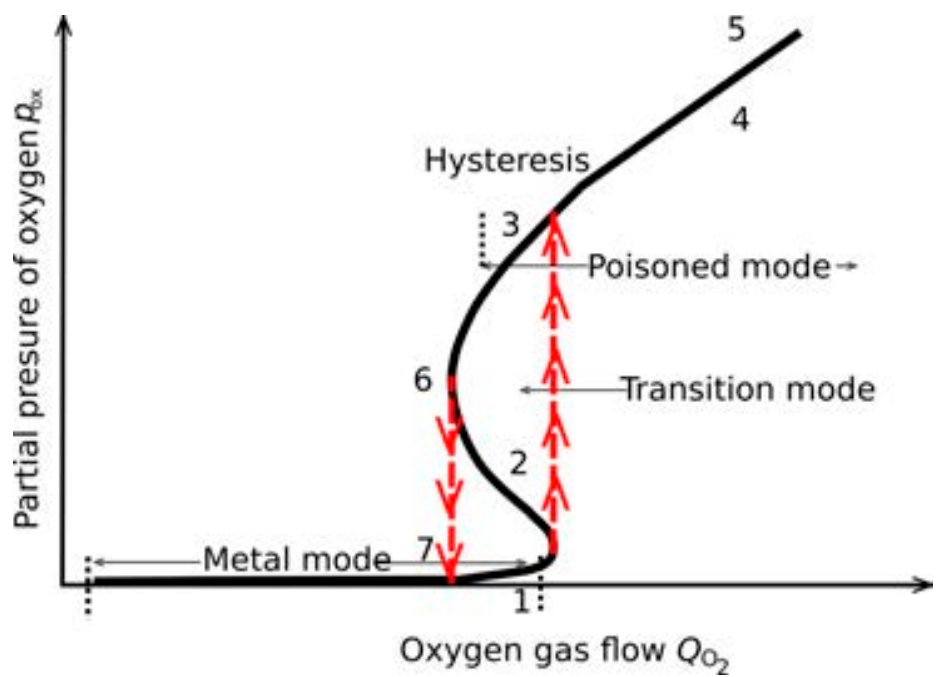

Figure 3: Sketch of a typical hysteresis in steady state (black line). If no fast feedback control is used, the partial pressure follows the red dashed lines from 1 to 3 when the oxygen flow is increased, and 6 to 7 when the flow is decreased. This exposes a hysteresis in the process.

An illustration of a typical hysteresis behavior of a reactive sputtering process inside a vacuum system can be seen in Figure 3. The partial pressure of oxygen in the vacuum system is displayed on the y-axis, and the oxygen gas flow rate is displayed on the x-axis. At the area marked as metal mode, there is no significant increase in the partial pressure of oxygen, even though oxygen gas is continuously added to the process. The reason for this is that the oxygen gets consumed by the sputtered material and the pump of the vacuum system. Since there is no or little oxygen bound to the target in this region, it is often referred to as the metal mode. As the oxygen is further increased to the point marked as 1 , there are three different levels $(1,2,3)$ in the S-shaped curve that the partial pressure can have at steady state. It is however very difficult without an automatic fast feedback regulation loop to follow this S-shaped curve manually by tuning the flow rate and observing the partial pressure. This region is called the transition mode and a small perturbation such as an arc can make the cathode jump from position 1 to 2 or 3 . If the oxygen gas flow is increased to higher values than at position 1, the partial pressure follows the red dashed line and jumps directly to position 3 . This region is called the poisoned mode, and the cathode is here fully oxidized. A further increase of the oxygen flow to the process linearly increases the partial pressure of the vacuum system. This is because no more oxygen can be consumed by the sputtering process. As the oxygen flow is decreased to 6 , the partial pressure follows the red dashed line to 7. A hysteresis between the two red dashed lines is then observed [20]. The reasons for this hysteresis is that the cathode is already oxidized at position 6 
and the deposition of titanium is less than at position 1 . When the cathode clean sputters itself the partial pressure of oxygen decreases as the cathode becomes more efficient at sputtering out titanium which consumes oxygen.

It is often desired to operate the cathode inside the transition regime, since the deposition rate is much higher compared to the poisoned regime. One other reason is that in the poisoned mode, the grown film can only be fully stoichiometric, but it is possible to deposit sub stoichiometric films in the transition and metal mode [22]. Since it is difficult to have a stable transition mode, it is difficult to control the film stoichiometry. Several techniques have previously been used to try to stabilize the process in the transition mode when depositing thin films with a magnetron. Smaller cathode surface areas has been shown to be more stable [23]. Using high powered pulsed sputtering has also been shown to stabilize this zone in certain parameter ranges [24] [25]. The utilization of a hollow cathode where inert gas flows through it in combination with separate injection of reactive gas from the cathode surface has previously given more stability of the reactive sputter process [26]. In paper 1, all of these beneficial effects are combined and a stable process in the transition regime was possible.

In the work in this thesis, the power supply that feeds DC voltage to the pulsing unit is operated in a constant average current mode. This leads to that the cathode discharge voltage changes when oxygen is introduced to the sputtering process. The main reason for this has been found to be due to a change in the secondary electron emission yield as the target gets oxidized [20]. The discharge voltage can be used to indicate the oxidation state of the cathode, but careful considerations of other parameters that influence the voltage has to be made. An increased voltage for a constant current leads to a higher average powers. Since a pulsed voltage is used another phenomenon also arises when oxygen is added to the sputtering process of titanium, and that is that the peak current value increases for a constant average current [27]. 



\section{Experimental setup}

The discharge parameters used in all papers were similar and is here by referred to as the standard parameters. A frequency of $1500 \mathrm{~Hz}$ was used with a pulse width of $80 \mu \mathrm{s}$. The power supply was operated in current regulation mode, and a constant current was set so that the average power to the cathode did not exceed $100 \mathrm{~W}$ when oxygen was added to the process. The average power to the cathode was around $93 \mathrm{~W}$ in the metal mode. This resulted in peak current values of around $10 \mathrm{~A}$ and discharge voltages in the order of $280 \mathrm{~V}$.

\subsection{High vacuum systems}

Two slightly different experimental setups were used in the appended paper 1 and paper 2. In paper 1, a stainless steel mesh (Figure. 4 a) was used around the growth zone of the particles. The exact function of this mesh is still unknown, however it has been found to increase the reproducibility of getting particles down on the substrate, compared to not using anything at all. 


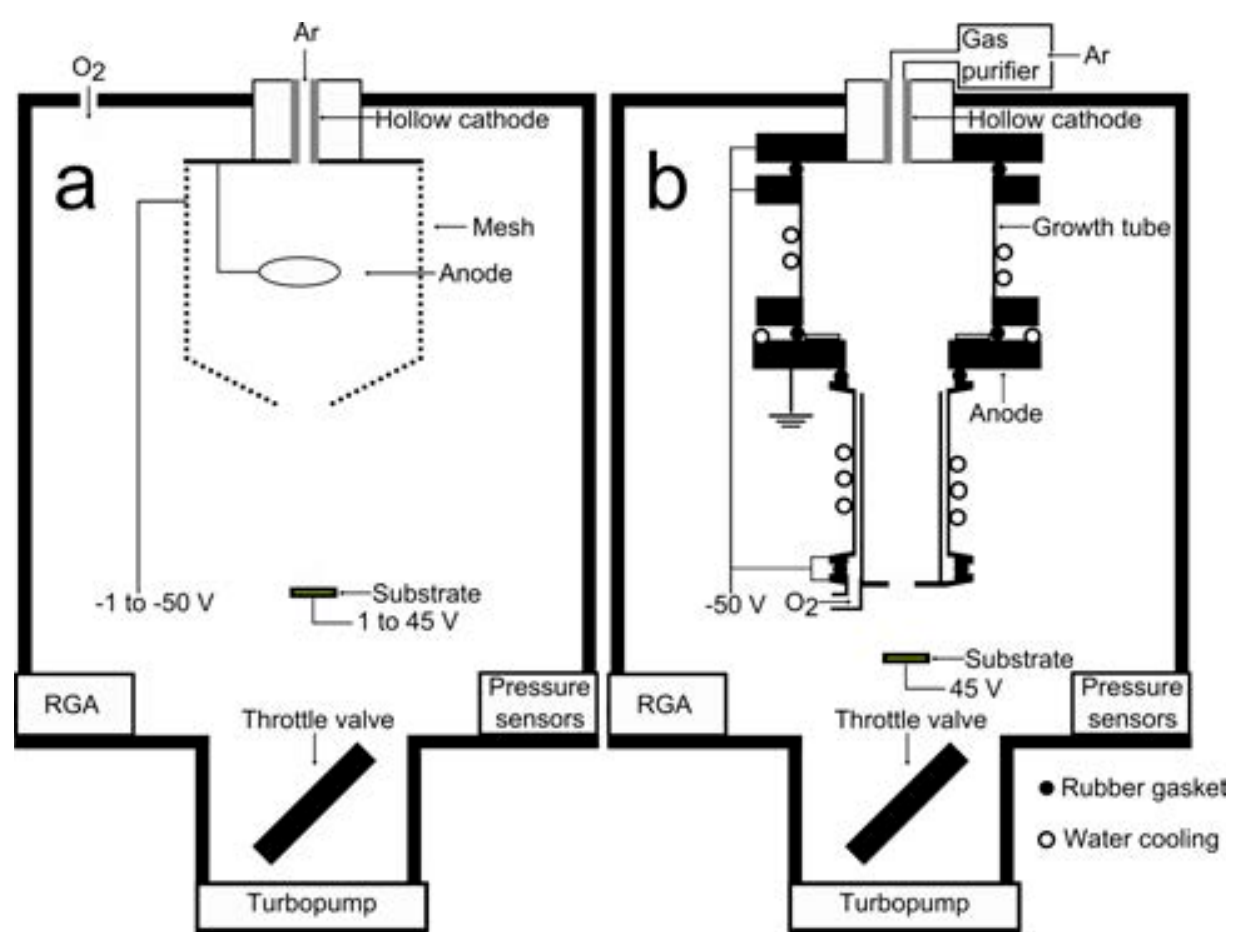

Figure 4: The experimental setups used. With the mesh and anode ring (a) used in paper 1. The experimental setup with the growth tube (b) used in paper 2.

A negative bias voltage can be put on the mesh, and if the potential between the mesh and the cathode becomes higher than the mesh and anode, a portion of the discharge current can flow through it. Another difference in (a) is the positioning and shape of the anode. Here it is made out of a thin ring suspended on a wire. There were several problems with the experimental setup that needed to be addressed for the experiments made for paper 2. The main problem was low reproducibility between experiments which manifested itself as drifts in the discharge voltage and the particle size distributions as well as uninterpretable $\mathrm{x}$ ray diffraction patterns for particles produced without the addition of oxygen. This was believed to be mainly associated with fluctuations of the residual water in the vacuum system. To minimize the effects of the base pressure, a tube was put around the particle growth zone to prevent water vapour from diffusing in to the plasma and react with the particles and cathode. Several prototypes of this growth tube were tested and it was found that a tube with diameter of $40 \mathrm{~mm}$ was too narrow to use up in the expansion zone of the plasma. A tube of diameter $73 \mathrm{~mm}$ and length of $68 \mathrm{~mm}$ gave a sufficient expansion zone, that could be later narrowed down to $40 \mathrm{~mm}$ in the bottom part of the tube (Figure $4 \mathrm{~b}$ ). To focus the particles with the gas flow and to further suppress inflow of water the exit hole of the growth tube was narrowed to a diameter of $10 \mathrm{~mm}$. To make sure 
that the argon gas that was fed to the process was clean, a gas purifier was put on the gas line. Water cooling of the growth tube was necessary, since the discharge voltage drifted with temperature due to the change of the degassing rate from the tube walls. With this setup, it was possible to reach a cleaner state where particles did not nucleate without the addition of oxygen at the given argon gas flow. This is why there is an oxygen inlet in the lower part of the growth tube. Injecting oxygen outside of the system as in (a) did not influence the discharge inside the growth tube.

Other than these differences, the experimental setups are similar. It is possible to change the negative potential on both the growth tube and mesh to allow for size control. The chamber pressure at constant gas flow is set by restricting the pumping speed with the throttle valve. A differentially pumped residual gas analyser is used to monitor the partial pressure of the gases in the chamber. The substrates have a positive potential to attract the negatively charged particles.

\subsection{Ultrahigh vacuum system}

To be able to study how the nucleation of the nanoparticles occurs, cleaner experimental conditions were necessary. A complete re design of the experimental setup was made using only ultrahigh vacuum compatible components and was used to obtain the results in paper 3. A schematic drawing of the experimental setup is shown in Figure. 5. 


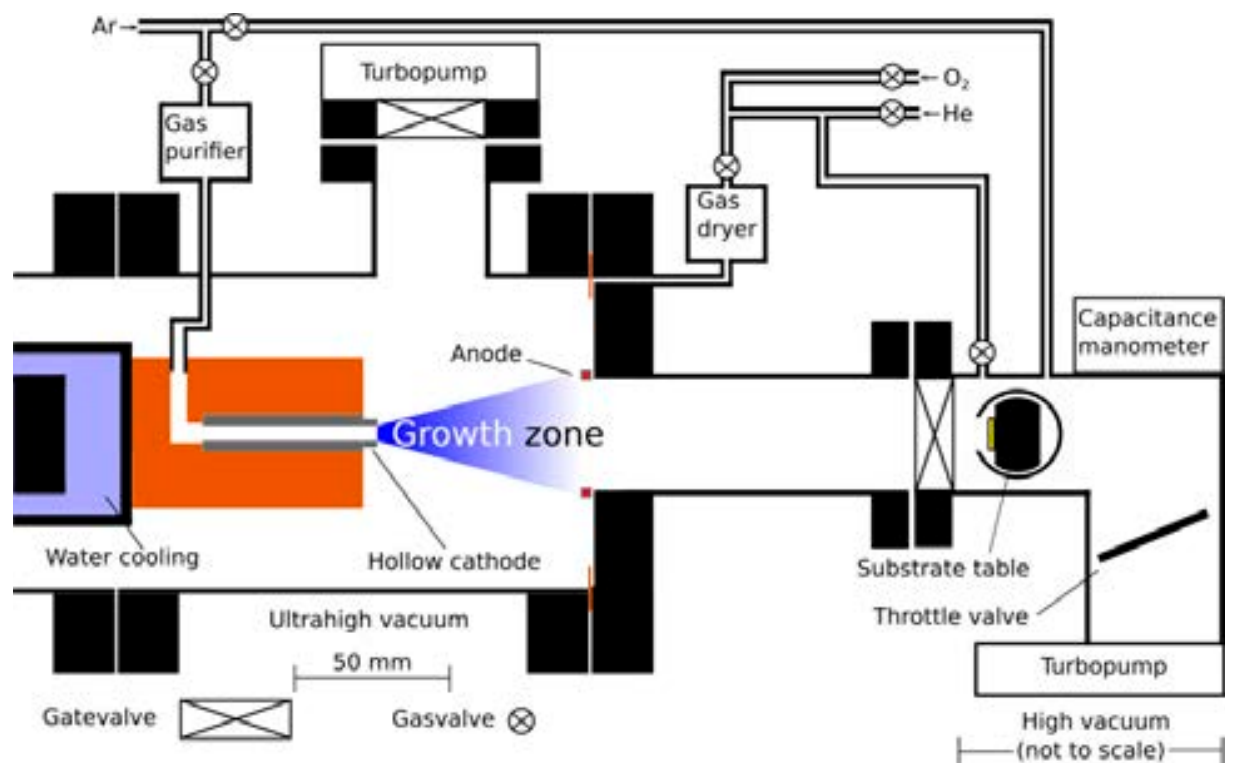

Figure 5: The nanoparticle growth zone is located in the ultrahigh vacuum part of the system. The substrate table is placed in a high vacuum system. The two regions are separated with a gate valve. Prior to experiments the gas lines are pumped with the high vacuum system and the gate valve separating the two systems are closed. When the process is running, this gate valve is opened while the gate valve in front of the turbopump is closed.

The nanoparticles nucleate and grow in the Ultrahigh vacuum region while the substrate table is placed in the high vacuum region. Diffusion of water vapour from the high vacuum part of the system is prevented by the argon and helium gas which flows counter to this diffusive flux. To ensure purity of the process gases, the gas lines are pumped with the high vacuum system all the way to the pressure regulator prior to the experiments. They also pass a gas purifier (argon) and a gas dryer (helium or oxygen) before entering the system. The nanoparticles are created in the growth zone and follow the electric field from the substrate bias and the direction of the gas flow to the substrate. The pressure is set and automatically regulated with a throttle valve connected to a capacitance manometer. The anode is put to a potential of $43 \mathrm{~V}$ while the substrates needs to have a potential in the order of $150-200 \mathrm{~V}$ to attract particles.

The chamber surrounding the growth zone of the particles can be cooled down by wrapping copper wires around it and submerging them in liquid nitrogen. The chamber can also be heated by wrapping it in resistive heating bands.

To replicate these experiments, it is important to know how to make a hollow cathode source. A regular cluster source or a magnetron sputter system designed 
for thin film depositions can easily be converted to use a hollow cathode instead of a planar target. This was done by making a hollow cathode adapter that fits on a regular sputter magnetron. The design conceived in this thesis is shown in Figure. 6 where (a) is a standard UHV compatible magnetron. The magnets were removed since they are not necessary and could complicate the understanding of the process. The ground shield was also removed. The reason for this is that magnetrons for thin film deposition are designed to operate at lower pressures If the pressure is higher, sputtering can occur between the ground shield and the surface marked (a) [28]. Instead of the ground shield, a piece of fiberglass weave was wrapped around the exposed surface. A cooling block (b) was machined from oxygen-free high conductivity copper. A thin piece of indium was placed between all mating surfaces that was designed to be thermal conductors. The hollow cathode (c) was placed in the machined groove and pressed down with the clamping block (d). A ceramic ring was placed behind the hollow cathode to prevent sputtering from the copper block.

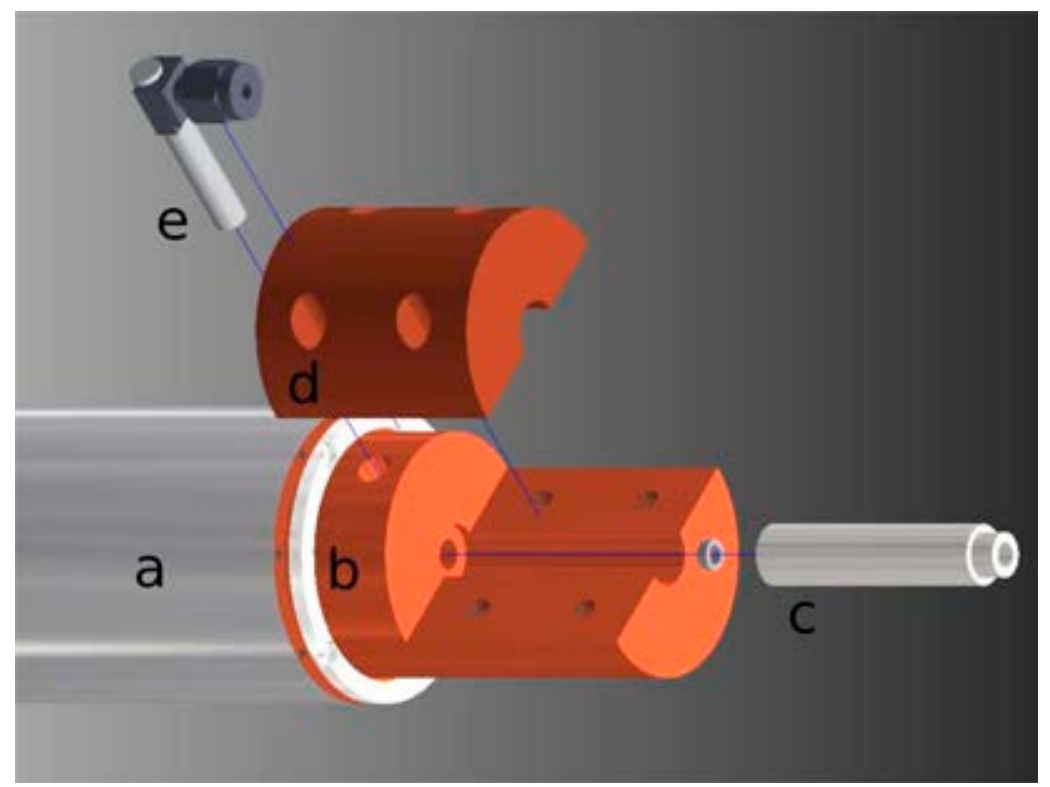

Figure 6: Exploded view of the hollow cathode adapter fitted on a regular magnetron (a). The cooling block (b) was attached like an ordinary target. The hollow cathode (c) was secured with the clamping block (d). Argon gas was injected through the Swagelok tube fitting attached to the ceramic rod (e)

The gas inlet was designed as a hole in (b) that guided the gas in to the backside of the hollow cathode. A piece of indium was used to seal the surfaces between the ceramic tube (e) and the copper block. A Swagelok tube connector was glued with PELCO high performance ceramic adhesive to the ceramic tube as the 
argon gas inlet. After attachment, the copper cooling block was wrapped with Kapton tape to prevent sputtering on its surface. 


\section{Nanoparticle nucleation and growth}

It has now been explained how the growth material gets ejected, and how the ejection of the growth material depends on the oxidation state of the cathode. In this section we will look closer on how this material is transformed into nanoparticles.

There are several problems associated with trying to model the nucleation inside this particular pulsed plasma process. The pulsing nature gives a time dependent variation of the density of ions, neutrals and electrons. The sputtered flux is also initially not in thermodynamic equilibrium with its surroundings, giving an unknown time and space dependent temperature [17]. The same is true for the clusters inside the sputtered flux. They will on average obtain a higher temperature than their surroundings due to exothermic reactions on their surface [29]. One other general problem is that the critical radius of a cluster is often explained by the liquid drop model where a surface tension is an important parameter. This becomes problematic when the nucleation occurs at small cluster sizes where a surface tension cannot be defined [28]. In addition to this, as the cluster radius becomes in the order of $<1 \mathrm{~nm}$, the thermodynamic derivation of the vapor pressure becomes questionable [30].

Due to the problems mentioned, a complete model is difficult to achieve. This thesis instead focuses on how the two first atoms that the nanoparticle will grow out of forms. Then how these two atoms continue to grow by atom attachment and the evaporation mechanism that prevents this growth process. Section 5 will only give a brief theoretical overview of how the nanoparticles nucleate and the theoretical results from paper 4 will be further presented in section 6.4 .2

\subsection{The creation of the first dimer}

The dimer is the first two atoms from which the nanoparticle continues to grow out of. We will here discuss how this formation process occurs. If two titanium atoms bind together, an exothermic reaction will occur that increases their energy to high enough levels for them to split apart. Thus this energy has to be quickly dissipated. If an inert gas atom such as argon is close to the two titanium atoms that are about to bind to each other, it can interact with the collision and carry away the excess energy as kinetic energy. These types of collisions are called 3-body collisions and are commonly used as the explanation for how the first dimers are created in cluster sources [31]. In paper 4 it is proposed that dimer formation can also occur by 2-body collisions, where a water molecule is 
involved. The titanium atom binds to the oxygen atom and a hydrogen molecule gets ejected, releasing the excess energy as kinetic energy. Since there are more titanium ions than titanium neutrals, we also explore how the ions charge interaction with the neutrals increases the amount of collisions.

The first two body collision we look closer into is the collision between a titanium atom and a water molecule. The titanium atom binds to the oxygen atom with a binding energy of $7.15 \mathrm{eV}$ and the hydrogen molecule gets ejected which carries away the excess kinetic energy. This reaction is depicted in 6

$$
\mathrm{Ti}+\mathrm{H}_{2} \mathrm{O} \rightarrow \mathrm{TiO}+\mathrm{H}_{2}
$$

The reason the hydrogen molecule has to be ejected is because this is the only reaction combination that was found to be exothermic, releasing an energy of $1.93 \mathrm{eV}$. The rate of dimer formation per cubic meter by this reaction is given by

$$
R_{\mathrm{TiH}_{2} \mathrm{O}}=\sigma v_{\mathrm{rel}} n_{\mathrm{Ti}} \cdot n_{\mathrm{H}_{2} \mathrm{O}}
$$

where $v_{\text {rel }}$ is the relative collision velocity between the titanium and the water molecule, $n_{\mathrm{Ti}}$ is the density of the titanium atoms, $n_{\mathrm{H}_{2} \mathrm{O}}$ is the density of the water molecules and $\sigma$ is the collision cross section [32].

From equation 7 it can be seen that the number of dimers created per second increases if the concentration of titanium atoms or the concentration of water vapour increases. If typical values are put into equation 7 , assuming that the collision diameter of titanium is the same as that of argon, we get collision rates of $1.3 \cdot 10^{17} \mathrm{~m}^{-3} \mathrm{~s}^{-1}$ in the UHV system if we assume that the sputtered material is within a sphere of the same radius as the hollow cathode and the temperature is $1250 \mathrm{~K}$. If the base pressure were two orders of magnitude higher, as in the high vacuum system, the rate of titanium oxide dimer production would also be two orders of magnitude higher.

Next we will look at the situation where titanium ions are involved as depicted by 8 .

$$
\mathrm{Ti}^{+}+\mathrm{H}_{2} \mathrm{O} \rightarrow \mathrm{TiO}^{+}+\mathrm{H}_{2}
$$

We have approximately an order of magnitude more titanium ions inside the plasma than titanium neutrals. In addition to this the collision cross section $\sigma$ between the titanium ion and the water molecule is also approximately an order of magnitude larger than the neutral collision cross section, due to the 
polarization induced by the positive titanium atom in the water molecule [33]. Thus there will be approximately 43 times more of reaction 8 than reaction 6 occuring giving a rate of $5.7 \cdot 10^{19} \mathrm{~m}^{-3} \mathrm{~s}^{-1}$.

The third means of dimer formation is by a 3-body collision process.

$$
\mathrm{Ti}+\mathrm{Ti}+\mathrm{Ar} \rightarrow \mathrm{Ti}_{2}+\mathrm{Ar}
$$

The reaction depicted in 9 shows that the titanium ion and atom bind together, while the inert gas atom, in this case argon, carries away the excess kinetic energy. The rate constant for this dimer formation is given by

$$
R_{\mathrm{Ti}_{2}}=n_{\mathrm{Ti}} n_{\mathrm{Ti}} b^{3} n_{\mathrm{Ar}} v_{\mathrm{rel}} \sigma
$$

where $n_{\mathrm{Ar}}$ is the argon density and $n_{\mathrm{Ti}}$ is the density of titanium neutrals. The factor $b$ is the distance where the Lennard-Jones potential is equal to the thermal energy [31]. If the same typical values are put into equation 10 , we get a collision rates of $5.3 \cdot 10^{17}$ collisions $\mathrm{m}^{-3} \mathrm{~s}^{-1}$ at pressures of $533 \mathrm{~Pa}$ of which is 4 times higher than the two body collisions with water involving neutrals in ultrahigh vacuum.

We will now take into account that ions can be involved in the 3-body collision, giving the following reaction

$$
\mathrm{Ti}^{+}+\mathrm{Ti}+\mathrm{Ar} \rightarrow \mathrm{Ti}_{2}^{+}+\mathrm{Ar}
$$

Only one of the colliding species can be positively ionized, else they would repel each other. The Lennard-Jones potential between the titanium atom and the titanium ion gives a larger interaction volume $b^{3}$ in equation 10 . The collision cross section, $\sigma$ will also be larger and since there are more ions than neutrals one $n_{\mathrm{Ti}}$ term becomes $n_{\mathrm{Ti}}{ }^{+}$which is larger. In the same example as previously taken, the rate constant of 11 will be $7.5 \cdot 10^{19}$ collisions $\mathrm{m}^{-3} \mathrm{~s}^{-1}$, which is 141 times higher than the 3 -body collision process involving neutrals and 13 times higher than the 2-body collision process involving ions.

It should be noted that there are margins of errors that should be included when estimating the collision rates above. One such error arises when determining the factors $K=v_{\text {rel }} \sigma b^{3}$ where for neutrals an error factor of $K \cdot 10^{ \pm 0.3}$ has previously been used [31]. There are also un-certainties in determining the temperature and densities of the colliding atoms and molecules in the experimental setup. However, what can be learned from equation (10) is that if dimer formation in an environment with low partial pressures of water is 
desired, it is beneficial to have a low temperature. This is because it increases the argon density $n_{\mathrm{Ar}}$ and the interaction volume $b^{3}$. It is also beneficial to operate the process at high pressures which increases the argon density $n_{\mathrm{Ar}}$ and decreases the diffusion rate of the titanium ions and neutrals, effectively increasing their densities as well. Lastly it is optimum to have half of the growth material ionized to maximize the product of $n_{\mathrm{Ti}} \cdot n_{\mathrm{Ti}^{+}}$. The involvement of ions increases the collision cross section and in the case of titanium, increases the dimer binding energy which increases the interaction volume $b^{3}$.

For the first step in the nucleation process, dimer formation by 3-body collisions of neutrals is the most commonly used theory [31] [34] [35] [36] [37] [38] [39] [40] [41] [42] [18] [43] [44] [45]. It should however be noted that there are other theories that give alternative explanations. Recently, it has been suggested [46] that the first dimer that the nanoparticle continues to grow out of is $\mathrm{Ar}_{2}{ }^{+}$, which has been reported to have a binding energy of $1.5 \mathrm{eV}$. If the same $K$ value as in [46] is used, and under the assumption that we have an equal amount of argon ions as titanium ions, we get $2.4 \cdot 10^{23} \mathrm{Ar}_{2}{ }^{+}$dimers created $\mathrm{m}^{-3} \mathrm{~s}^{-1}$ which is 3200 times more than the $\mathrm{Ti}_{2}{ }^{+}$dimers. However, a problem arises when these dimers condenses their first titanium atom through the reaction $\mathrm{Ar}_{2}{ }^{+}+\mathrm{Ti} \rightarrow \mathrm{Ar}_{2} \mathrm{Ti}^{+}$. This reaction releases $7.93 \mathrm{eV}$ which will be converted to vibrational energy. To break one Ar bond of this complex only requires $0.32 \mathrm{eV}$ with the reaction: $\mathrm{Ar}_{2} \mathrm{Ti}^{+} \rightarrow \mathrm{Ar}+\mathrm{ArTi}^{+}$and to break the second $\mathrm{Ar}$ bond only requires $0.02 \mathrm{eV}$ through the reaction: $\mathrm{ArTi}^{+} \rightarrow \mathrm{Ar}+\mathrm{Ti}^{+}$. Thus the growth of titanium on ionized argon clusters was not deemed feasible.

Another theory is that dimers are ejected from the target while sputtering [46]. However this theory was ruled out, since the dimers would have to survive inside the hollow cathode, which was deemed un-likely due to the high temperature and high density of energetic ions and electrons.

Even if a dimer is created it has to grow to a certain size where the condensation rate is equal to the evaporation rate from the cluster. At this size, the cluster is said to have nucleated and the following section will cover the growth from dimers to this size.

\subsubsection{Growth to stable clusters}

In an oxygen starved environment, the dimer will most likely grow by inelastic collisions with titanium neutrals. This is inn spite of the fact that the collision 
rate between a neutral cluster and an ion or an ionized cluster and an electron will be more probable due to their higher density. Although the collision with an ion would add one atom, the subsequent recombination by pickup of an electron would remove one atom due to evaporation from the high recombination energy, thus giving no net growth rate at these small sizes.

When a cluster of a smaller size than what is thermodynamically stable binds to a titanium atom, it will heat up due to the chemical energy released from creating the bond.

$$
\mathrm{Ti}_{N-1}+\mathrm{Ti} \rightleftarrows \mathrm{Ti}_{N}^{\ddagger} \rightarrow \mathrm{Ti}_{N}
$$

This creates a hot cluster $\mathrm{Ti}_{N}^{\ddagger}$ that has to cool down before it can capture another titanium atom. The means of cooling is by collisions with the buffer gas such as argon or helium. During the time that the cluster is hot, there is a high probability that it evaporates, thus the reaction (12) can go in both directions [46]. In papers 3 and 4 , the evaporation of the hot clusters was found to be the bottleneck for nucleation, and it was shown that by decreasing the clusters vapor pressure by adding oxygen, or decreasing the cluster temperature by decreasing the gas temperature, helped this process. This will be further explained in section 6.4.2.

The following chain of reactions can be used to illustrate the cluster growth without writing out the intermediate step of cooling down a hot cluster.

$$
\mathrm{Ti}_{2} \rightleftarrows \mathrm{Ti}_{3} \rightleftarrows \mathrm{Ti}_{4} \rightleftarrows \mathrm{Ti}_{5} \ldots \rightleftarrows \mathrm{Ti}_{N-1} \rightarrow \mathrm{Ti}_{N}^{*}
$$

When the cluster reaches the size of $\mathrm{Ti}_{N}{ }^{*}$, the probability of evaporating one atom from its excited state is the same as the probability to cool down before this has happened. It is now defined as nucleated, and will on average only grow larger after this. Each step prior will have a higher evaporation probability, meaning that in the end, there will be significantly fewer clusters of size $\mathrm{Ti}_{N+1}{ }^{*}$ created than $\mathrm{Ti}_{2}$. The evaporation rate in every step will strongly influence the probability that a dimer nucleates.

To study the nucleation of nanoparticles in sputter plasma is of high technological interest. Prior to the results in this work, it was still an investigated process [47] [48] [43] [49]. For the synthesis of titanium, cobalt [47] and tungsten [50] nanoparticles it was previously found to be necessary to have a partial pressure of reactive gas such as oxygen or water vapor in order for particles to nucleate in a cluster source. For the synthesis of copper nanoparticles, oxygen was not found to be necessary, but it increased the nanoparticle mass deposition rate at certain partial pressures [41]. The 
explanation for this bottle neck in obtaining nanoparticles has by Peter et al. [47] previously been explained in the formation of the first dimers. They found that a titanium-titanium dimer has a low binding energy of $1.219 \mathrm{eV}$, while a titanium-oxygen dimer has a much higher binding energy of $6.908 \mathrm{eV}$. For the case of copper, the copper-copper dimer binding energy is $2.0834 \mathrm{eV}$ while the copper-oxygen dimer is not much higher with a binding energy of $2.974 \mathrm{eV}$. In addition to this, the sputter yield of copper is considerably higher than that of titanium, which gives a higher density of copper atoms that leads to a higher probability of two copper atoms colliding with each other. This was used to explain why titanium nanoparticles required a partial pressure of oxygen in order to nucleate and why copper nanoparticles did not [47]. It has thus previously been highlighted that the binding energy of the dimers play an important role in determining whether nanoparticles nucleate or not. However, in paper 3 and $\mathbf{4}$ we found that in our process, it is not the binding energy of the dimers that is the bottleneck, but rather the binding energy of the growing sub critical clusters.

\subsection{Particle charging}

If a particle is put inside a low temperature laboratory plasma it will typically acquire a negative charge. This is because the electrons in the plasma have a higher velocity than the ions which gives them a higher probability of colliding with a particle. As the particle has acquired a negative charge, it will start to repel electrons and attract ions. A positive ion sheath forms around the negatively charged particle. This sheath length is related to the Debye length, $\lambda_{\mathrm{D}}$ which is the distance where the negative charge of the particle is fully shielded by the positive ions [51].

$$
\frac{1}{\lambda_{\mathrm{D}}^{2}}=\frac{n_{\mathrm{e}} e^{2}}{\varepsilon_{0} k_{\mathrm{B}} T_{e}}+\frac{n_{\mathrm{i}} e^{2}}{\varepsilon_{0} k_{\mathrm{B}} T_{\mathrm{i}}}
$$

Where $n_{\mathrm{e}}$ is the electron density $n_{\mathrm{i}}$ is the ion density, $T_{\mathrm{e}}$ is the electron temperature and $T_{\mathrm{i}}$ is the ion temperature, e is the elementary charge, $\varepsilon_{0}$ is the dielectric constant of the vacuum and $k_{\mathrm{B}}$ is the Boltzmann constant [52]. The charge of a particle is determined by the balance of the electron and ion currents. The particles negative charge reduces the electron current, so that the particle obtains no net currents at steady state. The correct equations to describe the ion and electron current to the particle depend on its size relative to the Debye 
length. If the particle is small (or the Debye length is long) $\left(\lambda_{\mathrm{D}}>>r\right)$, the ions will start to orbit around the negatively charged particle and hit it with an incidence angle. The theory used to describe this is called Orbital Motion Limited (OML) [51]. To get the OML current in the case for a Maxwellian velocity distribution it is necessary to integrate for all velocities from every charge contribution for the full solid angle $4 \pi[52]$.

If the particle is large enough to obtain the floating potential of the plasma, the electron (15) and ion (16) flux to the particle is given by:

$$
\begin{gathered}
I_{\mathrm{e}}=-\pi r_{\mathrm{NP}}^{2} n_{e} e \sqrt{\frac{8 k_{\mathrm{B}} T_{\mathrm{e}}}{\pi m_{\mathrm{e}}}} \exp \left(\frac{e V}{k_{\mathrm{B}} T_{e}}\right) \\
I_{\mathrm{i}}=\pi r_{\mathrm{NP}}^{2} n_{\mathrm{i}} e \sqrt{\frac{8 k_{\mathrm{B}} T_{\mathrm{i}}}{\pi m_{i}}}\left(1-\frac{e V}{k_{\mathrm{B}} T_{\mathrm{i}}}\right)
\end{gathered}
$$

Where $r$ is the particle radius $V$ is the floating potential, $m_{i}$ is the ion mass and $m_{\mathrm{e}}$ is the electron mass [51].

Due to the electron and ion currents, the particles in a low temperature laboratory plasma will on average obtain a negative charge. However, if one look at a single particle, the charging is a discrete process [51]. This becomes significant for particles in the size range of 1-2 $\mathrm{nm}$ in diameter, since such small particles can only hold up to one or two charges [53] [54]. This means that particles can obtain neutral, or even in some special cases positive charge if they statistically just happen to collide with more ions [51].

Lastly it shall also be noted that the particle charge depends on the number density of particles in the plasma. By looking at the condition for quasi neutrality:

$$
n_{e}=n_{\mathrm{i}}-Z_{\mathrm{p}} n_{\mathrm{p}}
$$

Where $Z_{\mathrm{p}}$ is the particle charge and $n_{\mathrm{p}}$ is the number density of particles in the plasma. For this quasi neutrality to hold when the total particle charge density $Z_{\mathrm{p}} n_{\mathrm{p}}$ approaches the same order of magnitude as the charge density of ions $n_{\mathrm{i}}$, the plasma will get depleted of electrons, reducing $n_{\mathrm{e}}$. Since the particles obtain their charge from the current from this depleted regime, the absolute value of the particles floating potential will decrease [52]. 


\subsection{Surface Growth and cooling}

When the particle grows large enough to obtain a negative charge, the flux of ions from the OML current will be the main contribution of growth material to the particle. Why this is the case can be understood by looking at the collision cross section for ions and neutrals on a charged particle. The collision cross section of a neutral is given by

$$
\sigma_{\text {neutral }}=\pi r_{\mathrm{NP}}^{2}
$$

Which is the same as the geometrical cross section. By using a simplified equation for the floating potential

$$
V=-\frac{K_{1} k_{\mathrm{B}} T_{\mathrm{e}}}{e}
$$

Where $K_{1}$ is a function of the ion mass and the ratio between the electron and ion temperature. For titanium and in the parameter regime worked in, a value of $K_{1}=2.48$ can be used. The collision cross section for a positive ion on a negatively charged is then given by

$$
\sigma_{\text {ion }}=\pi r_{\mathrm{NP}}^{2}\left(1+K_{1} \frac{T_{\mathrm{e}}}{T_{\mathrm{i}}}\right)
$$

The collision cross section will thus be much larger, two orders of magnitude for ions compared to neutrals [8]. This has shown to give radial growth rates in the order of $470 \mathrm{~nm} / \mathrm{s}$ when a copper hollow cathode was used [9].

The electron and ion currents will cause heating of the particle. It is here even for large particles important for them to be able to cool down. This is significant in high density plasmas, since there are less gas atoms that can cool the particle and a higher ion current that heats it which could lead to evaporation [51].

Excluding evaporation, there are two main mechanism that the nanoparticle can cool down with: collision with colder gas atoms and emission of electromagnetic radiation. If the radius of the nanoparticle is much smaller than the mean free path $\left(r_{\mathrm{NP}} \ll \lambda\right)$ The cooling rate by collisions [55] can be expressed by

$$
q=\alpha \pi r_{\mathrm{NP}}^{2} p \sqrt{\frac{2 k_{\mathrm{B}} T_{\mathrm{g}}}{\pi m_{\mathrm{g}}}}\left(\frac{\kappa+1}{\kappa-1}\right)\left(\frac{T_{\mathrm{NP}}}{T_{\mathrm{g}}}-1\right)
$$


Where $m_{\mathrm{g}}$ is the mass of the cooling gas atom. The factor $\kappa$ is the specific heat ratio which depends on the number of active degrees of freedom of the cooling gas molecule. The gas constant $\alpha$ is the thermal accommodation coefficient which is a measure of the efficiency of the gas molecule to transfer heat. The value of $\alpha$ has been measured on heat transfer from a stainless steel surface which resulted in $\alpha=0.866$ for argon gas and $\alpha=0.360$ for helium [56]. Helium is often used as a cooling gas due to its high thermal conductivity of $0.1557 \mathrm{Wm}^{-1} \mathrm{~K}^{-1}$ compared to argon $0.0177 \mathrm{Wm}^{-1} \mathrm{~K}^{-1}$ at room temperature, which is $780 \%$ higher than argon [57]. But for the sake of cooling a nanoparticle, helium makes less of a difference with only a $31 \%$ increase in the cooling rate compared to argon.

The expression for the radiative cooling term [58] is given by

$$
q_{\mathrm{rad}}=4 \pi r_{\mathrm{NP}}^{2} \varepsilon_{\mathrm{NP}} \sigma_{\mathrm{b}}\left(T_{\mathrm{NP}}^{4}-T_{\text {wall }}^{4}\right)
$$

Where $\sigma_{\mathrm{b}}$ is the Stefan-Boltzmann constant and $\varepsilon_{\mathrm{NP}}$ is the emissivity of the nanoparticle. The emissivity is a size dependent property when the wavelength of the emitted radiation is larger than the size of the particle, resulting in that smaller nanoparticles have a lower emissivity [58].

For the temperatures, gas pressures and sizes of the particles discussed in this thesis, the cooling mechanism is dominated by conduction. 



\section{Results and discussion}

In this chapter, the results from the four papers are discussed in combination with un-published results related to the process. First, the influence of the reactive gas on the sputtering process will be presented followed by different means of controlling the particle size. After this the reactive gases influence on the nanoparticles crystal structure, size and stoichiometry is presented which is followed by a discussion that highlights the problems associated with them. It is then shown how to grow titanium nanoparticles in an oxygen starved environment to resolve these issues. Lastly two examples of how the process can be used in technological applications is given.

\subsection{Influence of reactive gases on the cathode}

The influence of reactive gases on the nanoparticles and the synthesis process was prior to this work unknown for this pulsed hollow cathode synthesis process. But, for the synthesis of titanium, it was found to be one of the most important process parameter.

First we will look at the influence of oxygen flow on the discharge voltage and the oxygen partial pressure inside the vacuum system. This experiment was done with the mesh (Figure. 4 a), so that the oxygen flown in to the chamber could react with the plasma and be monitored with the residual gas analyser. 


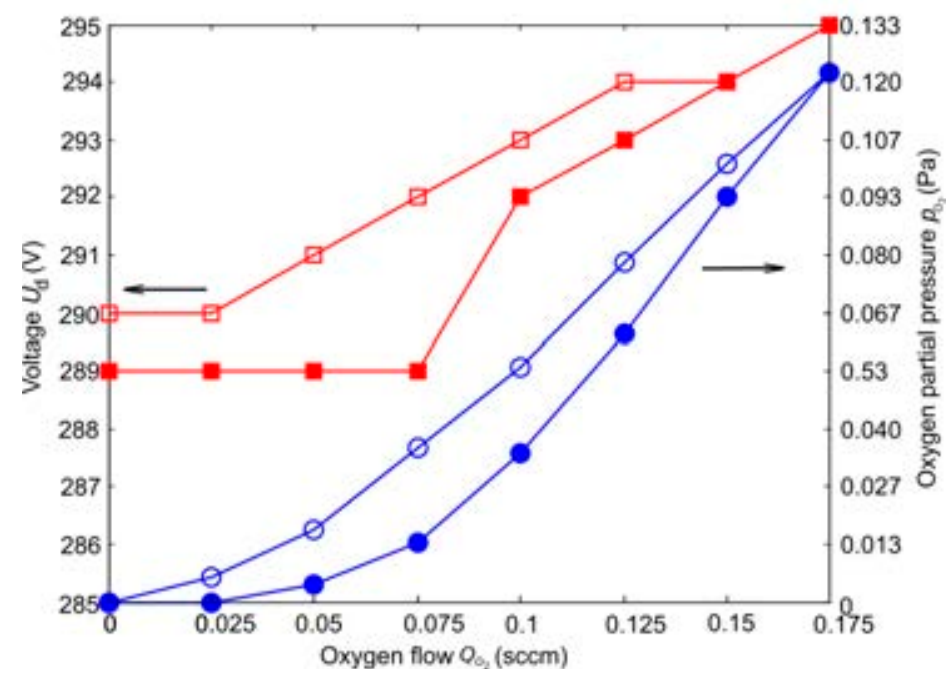

Figure 7: Oxygen partial pressure (blue circle) and cathode discharge voltage (red square) as a function of oxygen gas flow. The cathode voltage and the partial pressure increases with increasing oxygen gas flow (filled markers). When the oxygen gas flow decreases (open markers), a small hysteresis is found.

In Figure. 7 it can be seen from the red curve that the cathode indeed reacts with the oxygen which changes its discharge voltage. It should be noted that the plateau at $289 \mathrm{~V}$ was not always there and sometimes the voltage change was observed at lower gas flows than $0.075 \mathrm{sccm}$. This implies that to only have an inert gas flow of $90 \mathrm{sccm}$ through the hollow cathode does not fully suppress oxygen from reacting with it. At the highest reactive gas flow of $0.175 \mathrm{sccm}$, the cathode is still in the transition mode and a further increase would increase the discharge voltage. When the gas flow is decreased (open markers) a hysteresis in the discharge voltage can be seen. By looking at the blue curve which shows the oxygen partial pressure of the chamber, a small hysteresis is also observed. However, this hysteresis is nothing like the ones typically seen in magnetron discharges, and if a longer waiting time between the measurement points were made, the hysteresis vanished. To grow fully stoichiometric titanium dioxide nanoparticles, it was not necessary to use higher gas flows than $0.125 \mathrm{sccm}$, at an argon gas flow of $90 \mathrm{sccm}$. This means that the cathode can be operated in the transition mode while still producing fully stoichiometric particles which allows for a higher deposition rate. It should however be noted that the deposition rate decreased when fully stoichiometric titanium dioxide nanoparticles were synthesized, but no quantification of the magnitude has been made. The deposition rate further decreased for even higher oxygen flows, which is also evidence for that the cathode had not yet reached the poisoned mode when fully stoichiometric titanium dioxide particles where produced. 
If the same experiment was run with the growth tube attached, the discharge voltage (red square) and partial pressure (blue circle) followed the curves in Figure. 8. It is clear that the discharge voltage does not get affected by the partial pressure of oxygen outside of the growth tube.

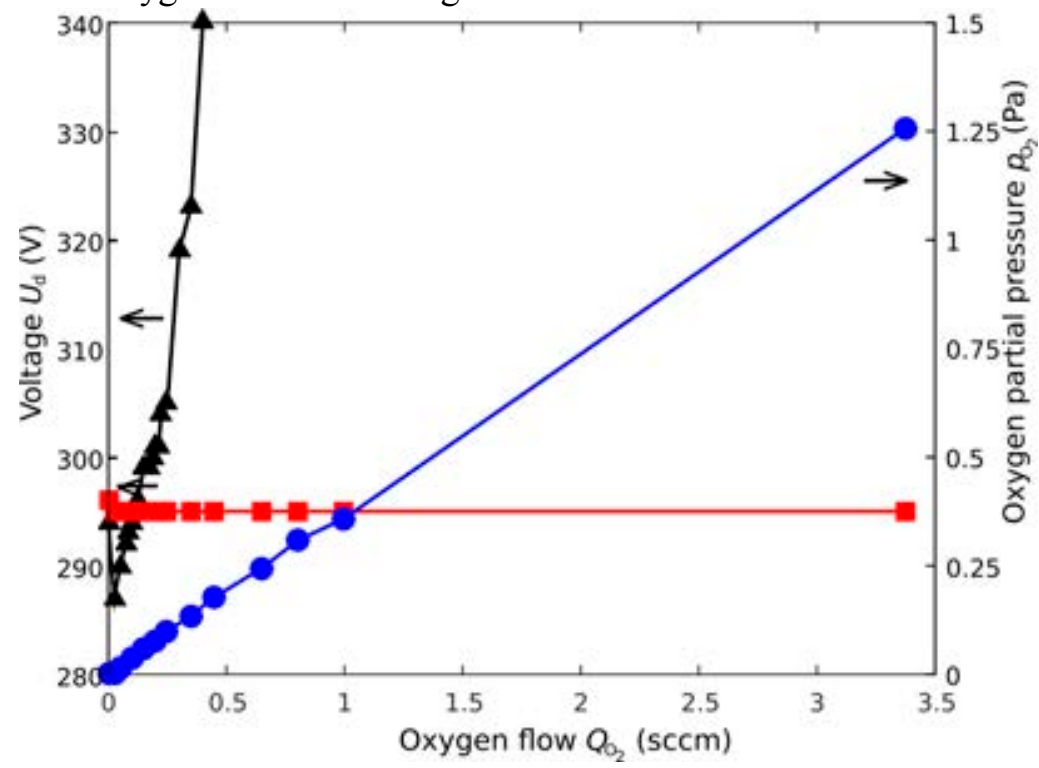

Figure 8: Oxygen partial pressure (blue circle) vs cathode discharge voltage (red square) as function of oxygen gas flow with the growth tube. The cathode discharge voltage without the growth tube is marked as black triangles.

It is thus safe to assume that the growth tube protects the cathode from external oxygen partial pressures of at least $1.25 \mathrm{~Pa}$ at an argon gas flow of $90 \mathrm{sccm}$. For comparison, the discharge voltage without the growth tube is plotted (black triangle) in the same graph. Already at $0.4 \mathrm{sccm}$, the cathode started to arc and the experiment had to be stopped. This result show that any fluctuation of the base pressure outside of the growth tube can be neglected. The only contaminants that could react with the particles is thus the ones desorbed from the inside of the growth tube. This led to a higher reproducibility and also the possibility to operate the discharge at clean conditions where the oxygen content was too low for nucleation to occur at the given argon gas flow. 


\subsection{Size control}

The ability to control the nanoparticles size is one of the most important factors that determines the properties they exhibit. It has previously been shown that for copper nanoparticles produced with a copper hollow cathode, the pulse parameters such as frequency can be used to change the nanoparticle size distribution [8]. This approach was also tested for the titanium hollow cathode, but the results were inconclusive. One major reason that these experiments did not work for titanium was that if the discharge parameters were altered so that the amount of sputtered titanium decreased, the cathode went in to the poisoned mode. Because of this, other means of size control had to be investigated for titanium.

Size control by changing electrical potentials around the growth zone will first be presented, then a discussion about the influence of pressure and gas flow on the nanoparticle size will be made.

\subsubsection{Size control by changing the mesh bias}

A compilation of nanoparticle size distributions for different mesh biases can be seen in Figure. 9. The open markers represent particles produced at an oxygen gas flow of $0.05 \mathrm{sccm}$. The filled markers represent particles produced at an oxygen flow of $0.15 \mathrm{sccm}$. No trend in the size variation with increasing oxygen gas flow can be seen. There are some size fluctuations between experiments on the same parameters and the fluctuations when oxygen is introduced is in the same order. 


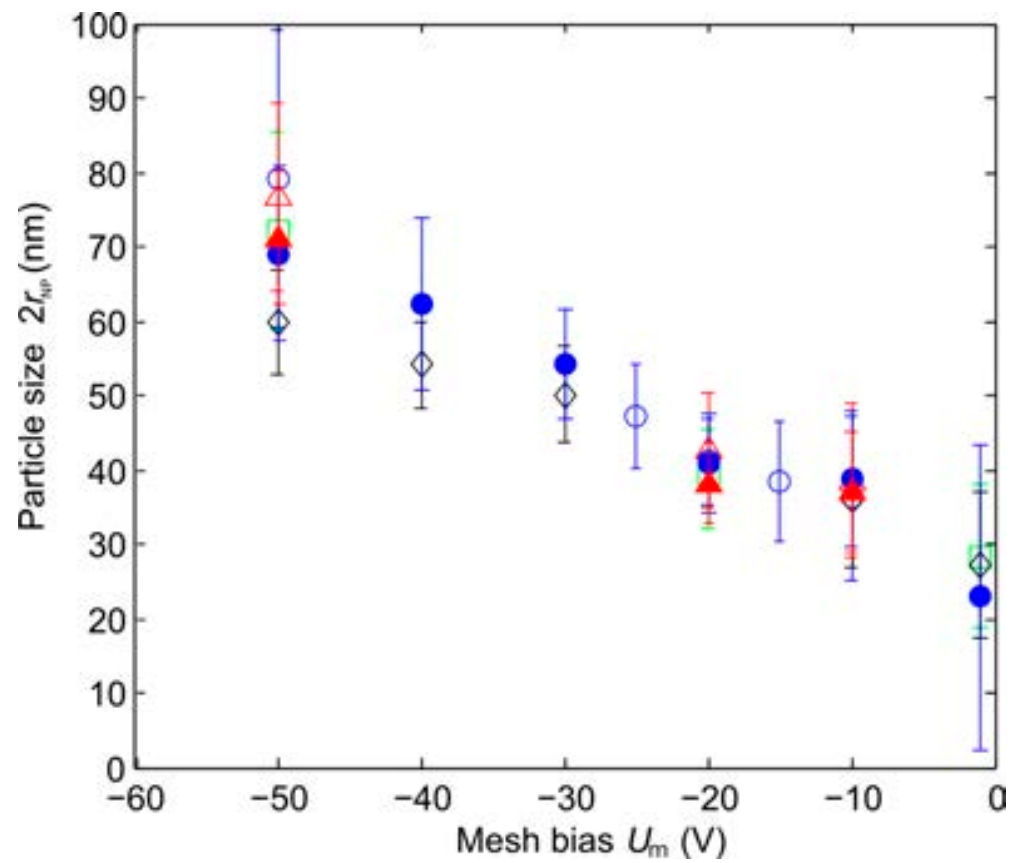

Figure 9: Nanoparticle size as a function of mesh bias for an oxygen flow of $0.05 \mathrm{sccm}$ (open markers) and $0.15 \mathrm{sccm}$ (filled markers). No significant size change can be seen between the two flows. The nanoparticle size decreases with decreasing negative bias.

There is a clear trend that the size decreases linearly when the negative mesh bias voltage is decreased. The mesh was connected to an active clamp circuit, which allowed current to flow through it if the potential between the mesh and cathode became higher than the potential between cathode and anode. This current was measured and plotted in Figure. 10. It can be seen that at $-50 \mathrm{~V}$, all of the current passes through the anode. No current is passed through the mesh until the negative mesh bias is reduced to $-20 \mathrm{~V}$. The current then steadily increases with decreasing negative mesh bias. 

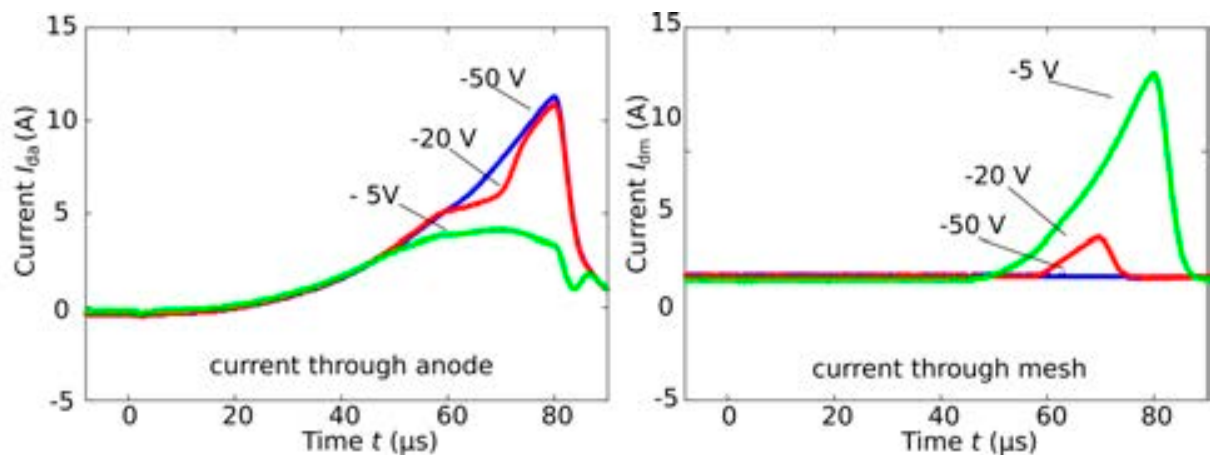

Figure 10: Current through the anode and current through the mesh during the pulse for different mesh biases.

This deflection of the current away from the anode ring and to the mesh also deflects the current away from the zone where the nanoparticles grow. This should decrease the electron temperature, which would lead to a lower ion current which is the main source of growth material to the particles. However, this cannot be the only explanation to this observation. The reason for this is that a size decrease is observed between -50 and $-20 \mathrm{~V}$ (Figure. 9), when all of the current still passes through the anode. The complete theory of how the mesh bias influences the particle size is unknown. By monitoring the partial pressure of oxygen in the process when the mesh bias was changed, it could be seen that it was constant. This means that the amount of sputtered titanium that reacted with this oxygen was independent of the mesh bias. The resulting benefit of this is that the particle size can be controlled without influencing the oxygen content of the particle.

\subsubsection{Size control by pressure and gas flow}

The argon gas pressure and flow was also found to be parameters that influenced the particle size. The following experimental results were obtained with the growth tube (high vacuum). First the influence of the pressure will be presented. Then experiments where the gas flow was varied followed by a simple theoretical model of the observed trends will be discussed.

In Figure. 11, the particles average size and size distributions as a function of pressure is presented for different argon gas flows. At low pressures and high argon gas flows, oxygen was needed to be added in order to synthesize particles. This has been marked with transparent markings in the figure. It can be seen that the particle size increases with increasing pressure for all gas flows tested. 


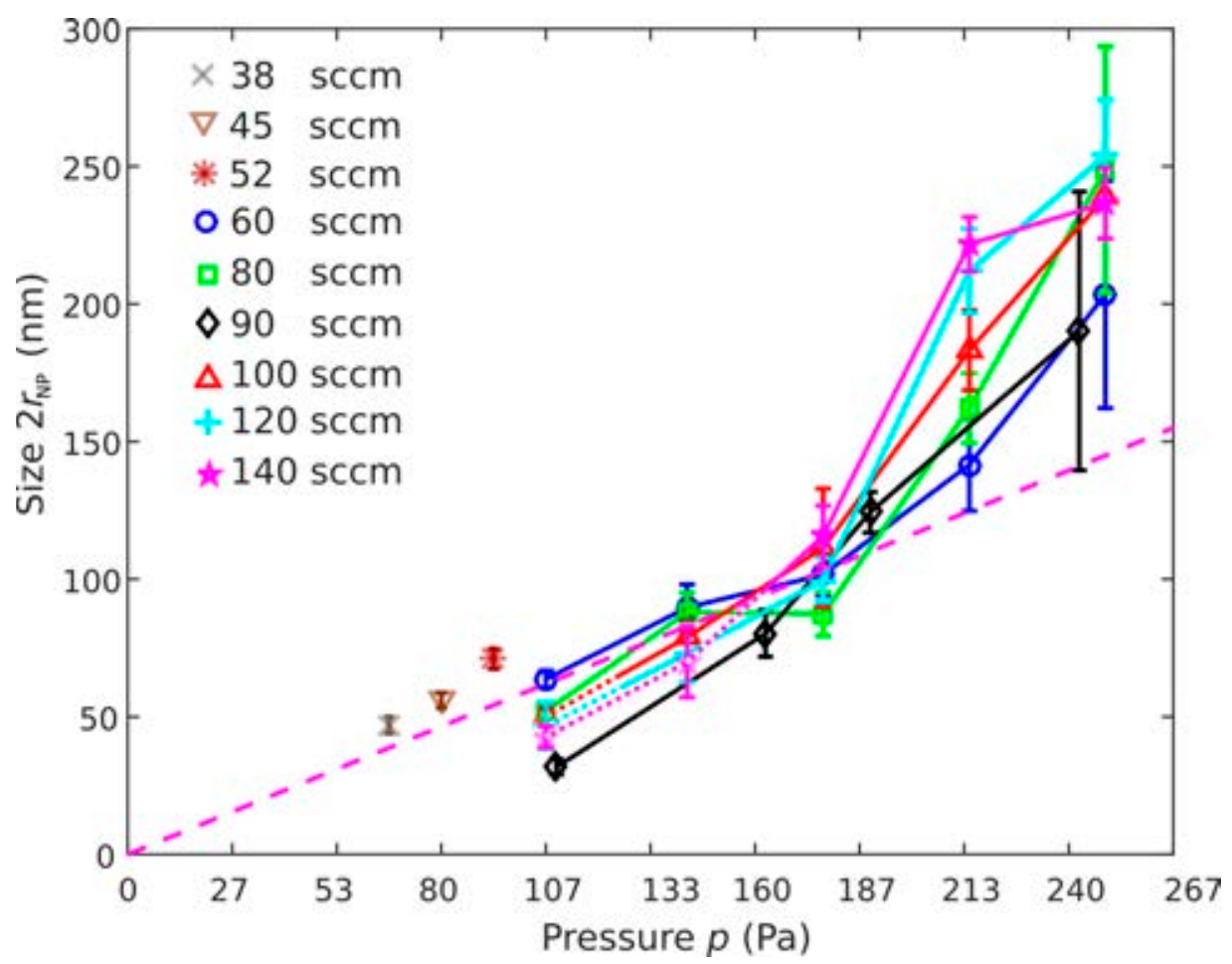

Figure 11: Particle size as a function of pressure for different argon gas flows. The transparent markings and dotted lines represent regions where oxygen had to be added. The dashed pink line is to show the deviation from a linear trend at $177 \mathrm{~Pa}$.

This size increase is after $177 \mathrm{~Pa}$ faster than linear as can be seen from the deviation from the pink dashed line. The size distributions also get broader at higher pressures. The size control that is possible by changing the pressure has a much larger range than the mesh bias, however, this pressure increase also increases the oxygen content of the particles when this is performed in the high vacuum system (not shown). The underlying reason for this increase in oxygen content is believed to be due to a lower pumping speed of reactive gases out of the growth tube at higher pressures. It should also be pointed out that the cathode discharge voltage increases when the pressure is increased which might be an indication of increased cathode oxidation at higher pressures.

The morphology of the particles also changed when the pressure was increased. In Figure. 12, nanoparticles synthesized at a argon gas flow of $90 \mathrm{sccm}$ at different pressures can be seen. 


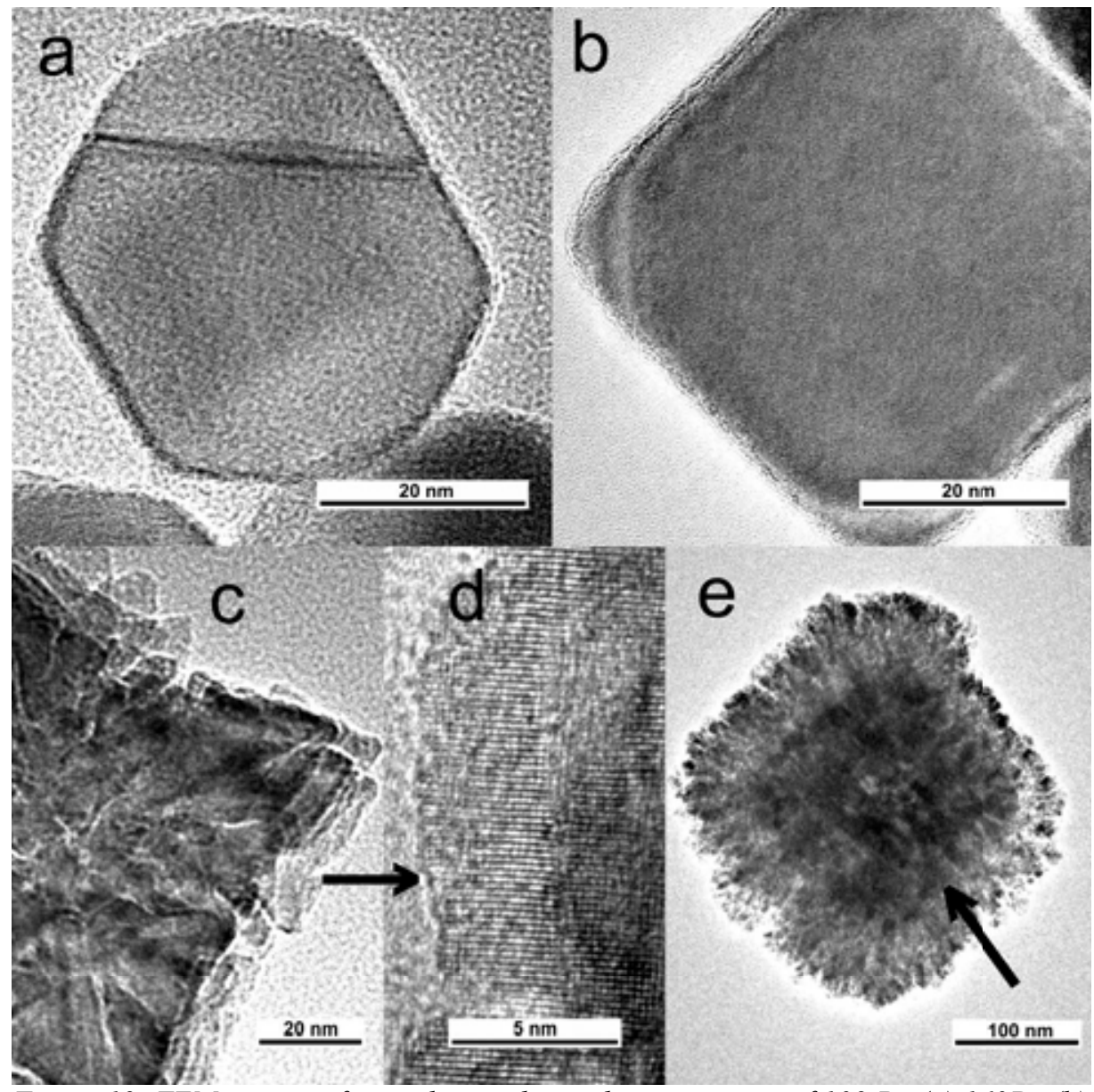

Figure 12: TEM images of particles synthesized at a pressure of $109 \mathrm{~Pa}(\mathrm{a}) 163 \mathrm{~Pa}$ (b) $189 \mathrm{~Pa}(\mathrm{c}),(\mathrm{d})$ and $243 \mathrm{~Pa}(\mathrm{e})$. A close up of the continued single crystal domain at the shell (d). Arrow in (e) shows the cubic core.

The particles start of as faceted crystals where most of them show multiple domains (a). As the pressure is increased, the particles obtain a cubic shape and the whole particle is a single crystalline domain (b). At the pressure of $189 \mathrm{~Pa}$, the particles obtain a faceted shape (c), however they are still single crystalline, as can be seen by the continued crystal domain in (d). When the pressure is increased to $243 \mathrm{~Pa}$, a new morphology emerges (e). This morphology has a single crystalline cubic core (arrow) and a poly crystalline shell and the outer shape of the particle is often referred to as a cauliflower shape.

This transition from cubic to cauliflower shaped particles with increasing pressure is very similar to the transition of cubic molybdenum particles to 
cauliflower shape (Figure. 17) when oxygen was introduced to the process. From the literature of thin film growth of molybdenum, it has been observed that columnar grown thin films get smaller columnar grain widths when the oxygen content of the sputtering process is increased. Since this grain width depends on the migration range of the adatoms on the surface, it was argued that since molybdenum has a high affinity to oxygen, the adatom mobility is suppressed by oxidation [59]. This can very well be the reason for why the nanoparticles transition from a cubic to a cauliflower morphology. A low adatom mobility will lead to that the adatoms bind to less preferential sites, which promotes poly crystallinity and thus a cauliflower shaped particle. Similarly in the case for titanium when the pressure is increased, the cooling rate of the particle will increase due to more frequent collisions with argon atoms. A lower temperature will decrease the adatom mobility [60] and thus promote poly crystallinity. In addition to this the deposition rate of titanium on the particle surface could increase due to the higher density of growth material. This would promote a more poly crystalline structure, since the adatoms would not have time to find their lowest energy state before getting covered by new atoms [19]. Experiments preformed in the ultrahigh vacuum system did not produce nanoparticles with a cauliflower morphology at higher pressures (187$666 \mathrm{~Pa}$ ). This indicates that oxygen is an important component that leads to this morphology

The influence of the argon gas flow on the particles will now be presented. The particle size as a function of gas flow for different pressures can be seen in Figure. 13. It was found that the size decreased with increasing gas flow at pressures below $143 \mathrm{~Pa}$. Surprisingly at $215 \mathrm{~Pa}$ a particle size increase with increasing gas flow was found. At the pressure of 177 and $249 \mathrm{~Pa}$ no clear trend could be seen. 


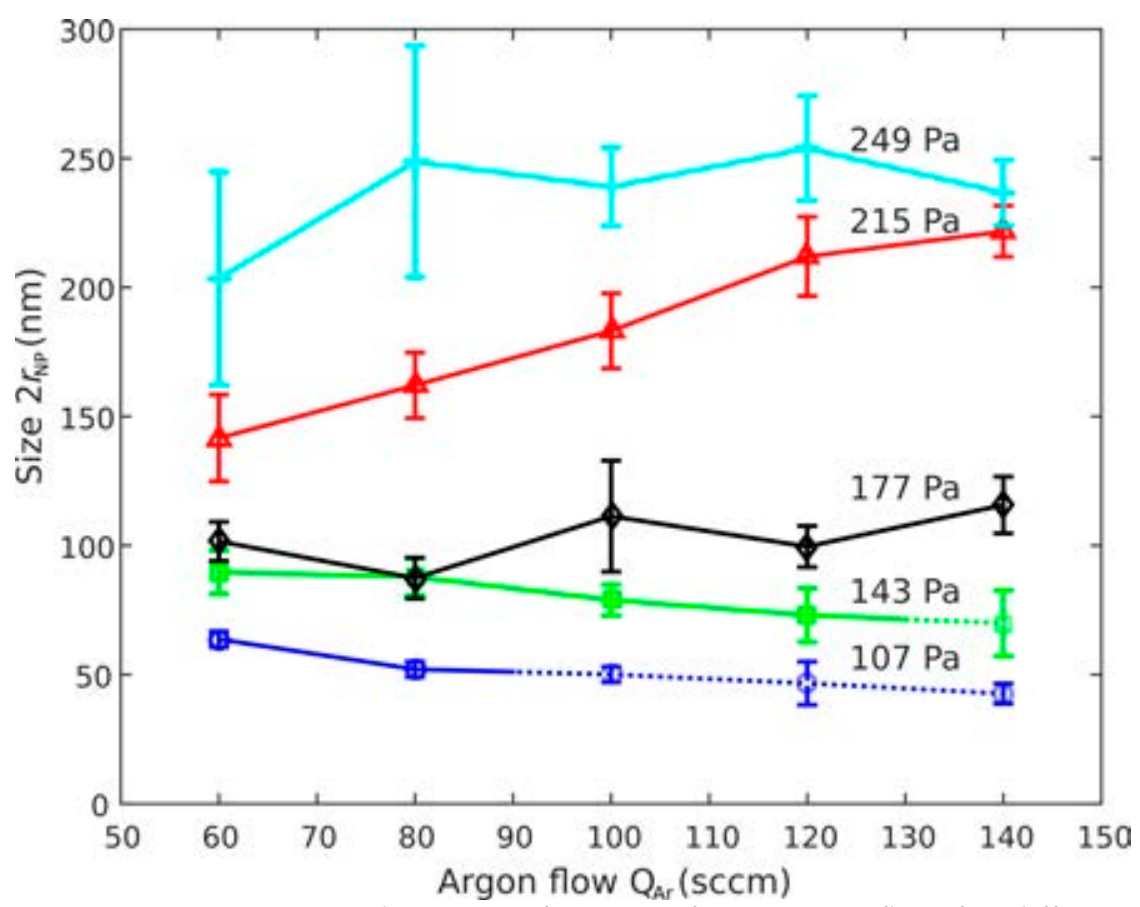

Figure 13: Particle size as function of argon gas flow for different pressures. Transparent markings and dotted lines represent regions where oxygen had to be added. At $107 \mathrm{~Pa}$ and $143 \mathrm{~Pa}$, the particle size decreases with increasing flow. At $177 \mathrm{~Pa}$, there is no clear trend in the size as a function of pressure. At $215 \mathrm{~Pa}$ there is a clear size increase with increasing gas flow.

In the cluster source literature, when a size decrease is found with an increasing inert gas flow, it is often argued to be due to a shorter residence time of the particles in the growth zone [61]. The same thing can be argued here as well at the lower pressures. Due to the design of cluster sources, the pressure is often set by the gas flow, and thus when the flow is increased, so is the pressure in the aggregation zone [40]. Thus the results in the literature cannot be directly compared to the results found here. The observed size increase could be due to a more efficient extraction of sputtered material from the hollow cathode at higher gas flows [62].

A simple model was proposed to explain the observed growth behavior of the particles. The assumptions made and the reasoning behind them can be found in the discussion section of paper 2. In short it is assumed that the particle growth rate can be explained by

$$
r_{\mathrm{NP}}=\left\langle d r_{\mathrm{NP}} / d t\right\rangle \cdot t_{\mathrm{res}}
$$


Where $r_{\mathrm{NP}}$ is the particle size, $d r_{\mathrm{NP}} / d t$ is the particle growth rate and $t_{\mathrm{res}}$ is the residence time of the particle in the growth zone. As was found in Figure. 11 , the size increases faster than linear with pressure. Thus both the growth rate and the residence time should increase linearly with pressure, in order to give a faster than linear increase. Why the growth rate would increase with pressure can be understood by that the diffusion rate of titanium ions from the cathode to the wall decreases with increasing pressure. Thus a higher density of titanium would be available at higher pressures which increases the growth rate. To explain why the residence time would increase with pressure one has to first mention that the sputtered material from the hollow cathode gets ejected by a puff, that can reach velocities of $190 \mathrm{~m} / \mathrm{s}$ [17]. The ejected material and the particles growing within it will then be slowed down by the gas in the growth tube, which has a much lower velocity. The friction between the gas and the particles will increase with pressure, and thus the particles will stay longer in the growth zone for higher pressures.

It is also possible to change the nanoparticle size by separately from the argon gas flow introducing helium in to the growth zone.

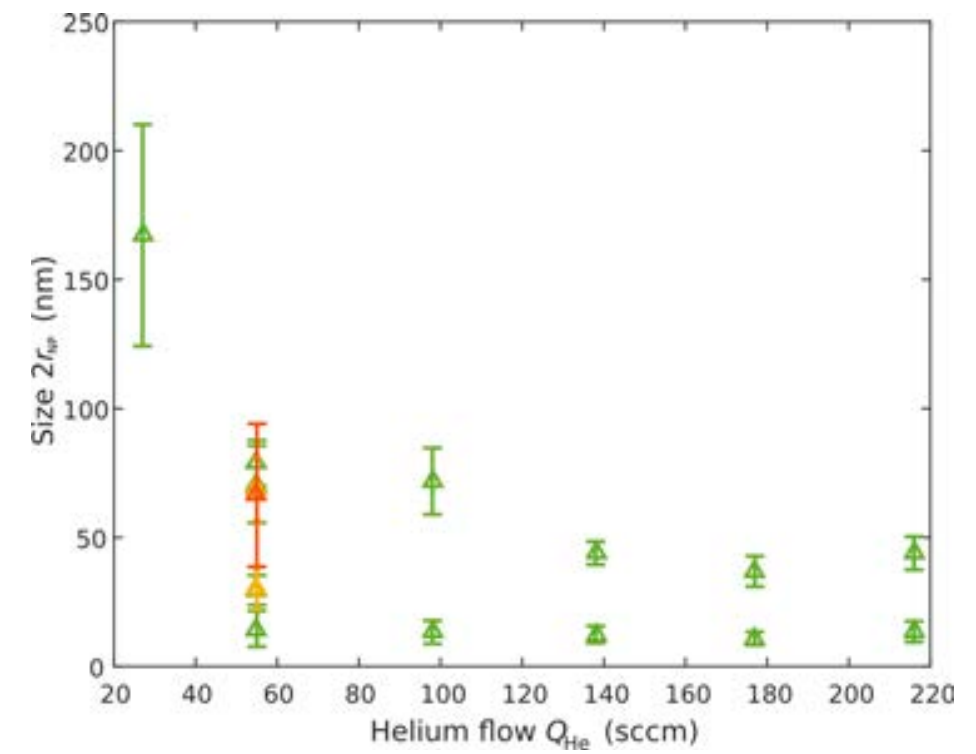

Figure 14: nanoparticle diameter as a function of helium gas flow. Between the gas flows of 55 to $218 \mathrm{sccm}$, there are 2 distinct particle size distributions on the substrates. The general trend is that the size decreases with increasing helium gas flow. 
The size decrease as a function of the helium gas flow can be seen in Figure. 14. These experiments where performed in the ultrahigh vacuum system at a pressure of $533 \mathrm{~Pa}$ and an argon gas flow of $10 \mathrm{sccm}$. In these experiments, there were often two distinct particle size distributions on the same sample seen by scanning electron microscopy, which is represented in the figure as two data points at the same helium gas flow. The decrease in the nanoparticle size can also be explained by an increase in the diffusion rate of the titanium ions. This is because the diffusion rate in helium is larger than the diffusion rate in argon.

\subsection{Influence of reactive gases on the nanoparticles}

In this section, a closer look is taken on the influence of the reactive gas on the growing nanoparticles. First the different crystal structures and the oxygen stoichiometry obtained are looked at. Then a discussion is made regarding whether the oxygen influences the particle size. Lastly, the practical problems caused by oxygen when operating in high vacuum will be highlighted.

\subsubsection{Influence on oxygen content and crystal structure}

When the nanoparticles are removed from the vacuum system in order to be analyzed in the microscope they are exposed to the ambient atmosphere. This causes them to quickly oxidize, usually creating a protective oxide shell, which prevents further rapid oxidation. Surprisingly, no pure titanium core and oxide shell were ever found on the titanium nanoparticles produced in the high vacuum system. This is different from the nanoparticles synthesized that can be found in the literature [40] [63]. The results from paper 3 show that the reason for the lack of a core shell structure in the nanoparticles is because the impurity level of the vacuum system is too high in combination with a too high gas temperature that prevents pure titanium nanoparticles to nucleate. 

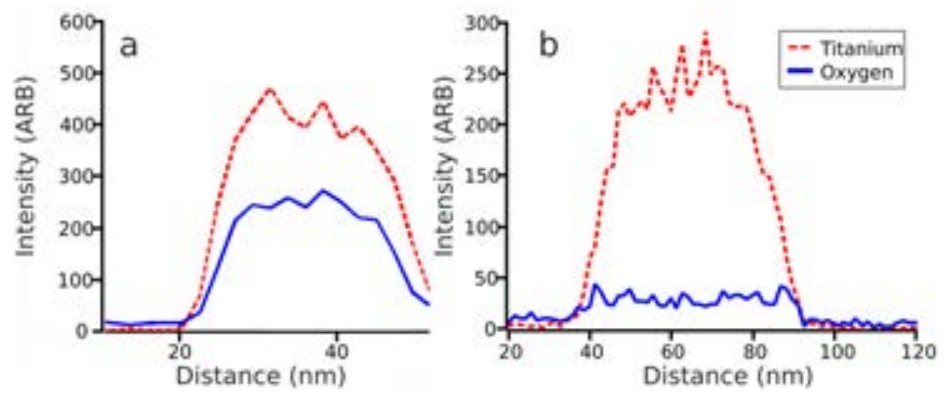

Figure 15: EDX line scan of the composition of a single typical nanoparticle synthesized in high vacuum (a) and ultrahigh vacuum (b). Red dashed line is the titanium composition, blue solid line is the oxygen composition.

The difference in the particle composition can be seen in Figure. 15 which was obtained by an energy dispersive X-ray spectroscopy (EDX) line scan. This shows the oxygen content and titanium content of a single nanoparticle. For the ones synthesized in high vacuum (a), the oxygen intensity follows the titanium intensity. This indicates that the composition of the nanoparticle is homogenously mixed. Comparing this to the one synthesized in ultrahigh vacuum (b), the titanium peak increases more steeply than the oxygen peak. This indicates that there is an oxide shell around the nanoparticle with a titanium rich core. It should be noted that just decreasing the base pressure was not enough to obtain nanoparticles in the ultrahigh vacuum regime. A high partial pressure of helium and a low argon gas flow was also necessary. This will be discussed in depth in section 6.4

If we now look at the X-ray diffraction patterns (Figure. 16) which show the crystal structure, we see that the particles synthesized in ultrahigh vacuum show clear titanium peaks. In the high vacuum system, where the nanoparticles oxygen content most likely came from the residual water, gave inconclusive results. Most of the time it was not possible to fit the peaks obtained to any reasonable material combination. Only once small peaks of titanium together with larger peaks of titanium oxide could be identified. Moving on to higher oxygen contents, where oxygen was intentionally introduced to the process, 


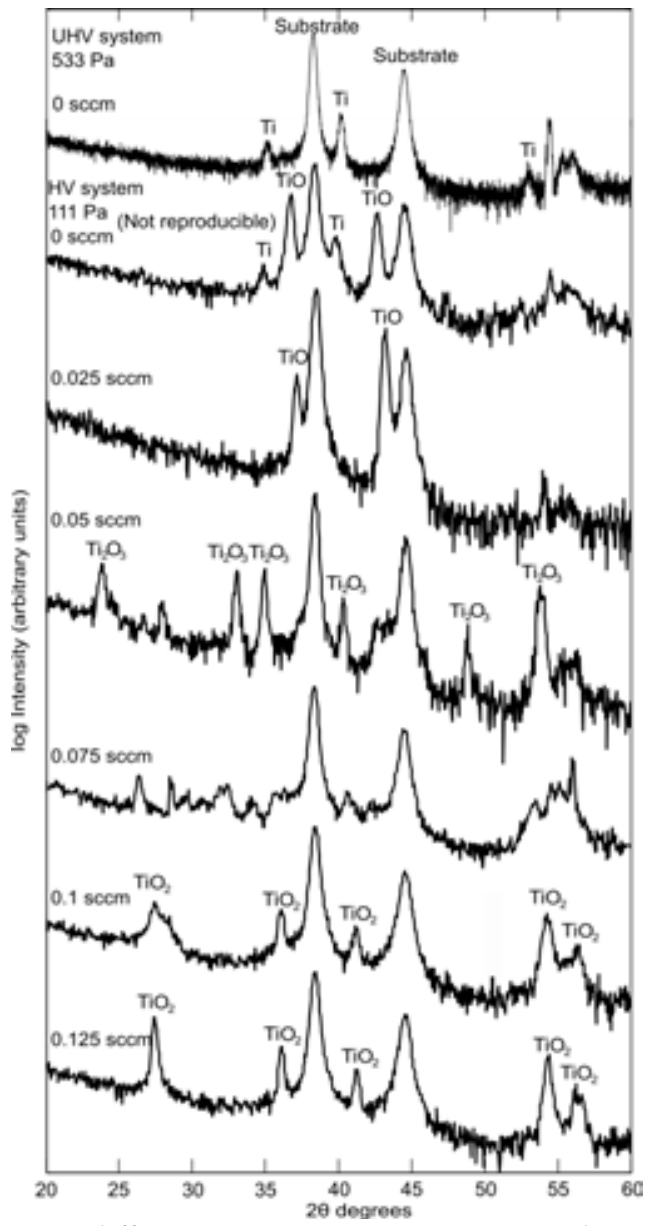

Figure 16: X-ray diffraction patterns on nanoparticles synthesized at different oxygen gas flows. A higher oxygen flow leads to higher oxygen containing crystal phases. The diffractogram at the top was obtained from particles produced in the UHV system at a pressure of $533 \mathrm{~Pa}$, a helium gas flow of $55 \mathrm{sccm}$ and an argon gas flow of $10 \mathrm{sccm}$. The rest of the diffractograms were obtained in a high vacuum system at a pressure of $111 \mathrm{~Pa}$ and an argon gas flow of $90 \mathrm{sccm}$.

only $\mathrm{TiO}$ phases were found at an oxygen gas flow of $0.025 \mathrm{sccm}$. At $0.05 \mathrm{sccm}$ $\mathrm{Ti}_{2} \mathrm{O}_{3}$ was the dominating phase. At $0.075 \mathrm{sccm}$, no peaks could be identified and it was probably a mixture of some intermediate phases. When the flow reached $0.1 \mathrm{sccm}$, and above, $\mathrm{TiO}_{2}$ nanoparticles in the rutile phase was found. This result demonstrates the possibility to control the oxygen content of the nanoparticles which is made possible since the cathode can stay in the transition mode without drifting to the poisoned mode. 
The titanium dioxide nanoparticles in the rutile phase were single crystalline. Some particles with twin planes or stacking faults could be found. The particles were fully oxidized all the way through without showing any signs of a less oxidized core [64].

For the titanium particles, there were no significant changes in the particle morphology when their oxygen content increased at the pressure of $110 \mathrm{~Pa}$ investigated. This observation is however not universally true, since nanoparticles synthesized with a molybdenum cathode had a profound morphological change. It should be noted that these experiments with molybdenum were run with different discharge parameters $(750 \mathrm{~Hz}, 20 \mathrm{~W})$ and argon gas flows $(5 \mathrm{sccm})$. Here, the particles transitioned from cubic to cauliflower shaped when an oxygen flow of 0.025 was introduced.

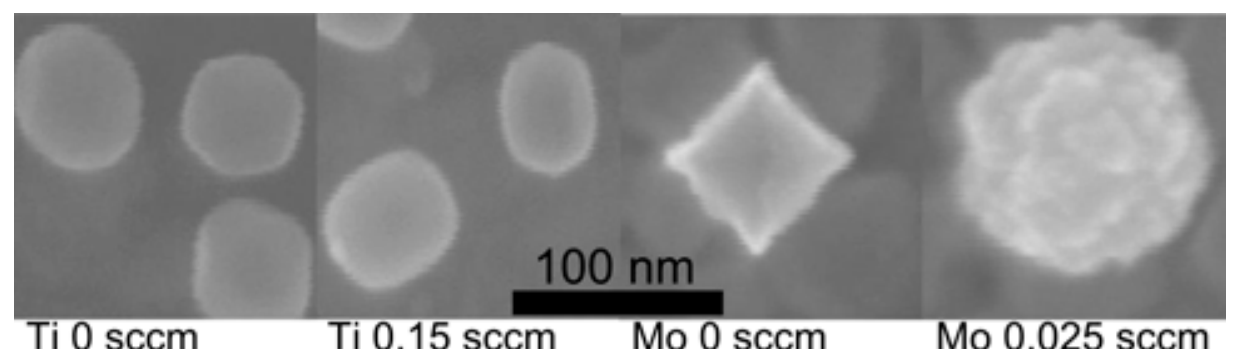

Figure 17: Nanoparticle change in morphology when oxygen was introduced to the process. No significant change could be seen for the titanium particles. The molybdenum particles transitioned from cubic to a cauliflower morphology.

This different behaviour between the two materials can be seen in Figure. 17. The only change in the titanium particles that was readily observed was that the perceived hexagonal shaped particles from the 2 dimensional images disappeared when oxygen was introduced and instead, some particles got a more oval shape. In the case of molybdenum, there was a clear and reproducible transition from cubic to cauliflower shaped particles.

\subsubsection{Oxygens influence on the particle size}

No size variation of the nanoparticles at different oxygen gas flows could be found in high vacuum when particles where synthesized with the titanium hollow cathode. This result is different from those in the literature where titanium oxide nanoparticles were synthesized in a cluster sources. When nanoparticles with sizes of less than $10 \mathrm{~nm}$ were produced, an exponential increase of the nanoparticle size with reactive gas flow was reported [65]. However, a size decrease has also been 
observed by another group [66]. When a molybdenum cathode was used in the experimental setup Figure. 4 (a), there was a size increase when oxygen was added to the process. Thus it should not be ruled out that oxygen can have a size increasing effect for different materials or different parameters. No simple explanation and general trend could be made, and the resulting particle size is probably a complicated interplay between particle nucleation and cathode poisoning, which could either increase or decrease the size depending on the experimental setup and the parameters used.

\subsubsection{The problems caused by residual gases}

It became evident that residual gases poses a major challenge when synthesizing nanoparticles of titanium in a high vacuum system. This section is devoted to some of the projects that failed due to a lack of realizing this at an earlier stage.

The first problem that will be highlighted is drift in the process manifesting itself as a decrease in the deposition rate and decrease in the nanoparticle oxygen content as a function of time. This is illustrated in Figure. 18. It can be seen that the black spot on the substrates, which is the area that gets covered with nanoparticles, decreases in size. In general, this means that there is less material on the substrates, however it is hard to quantify since the thickness of the black particle coating might vary. Correspondingly, if the average oxygen content of the nanoparticles deposited is estimated by energy dispersive X-ray analysis (EDX), a decreasing trend with time can be found. A similar trend was also found over a longer (monthly) period even if the chamber was vented between the experiments. 


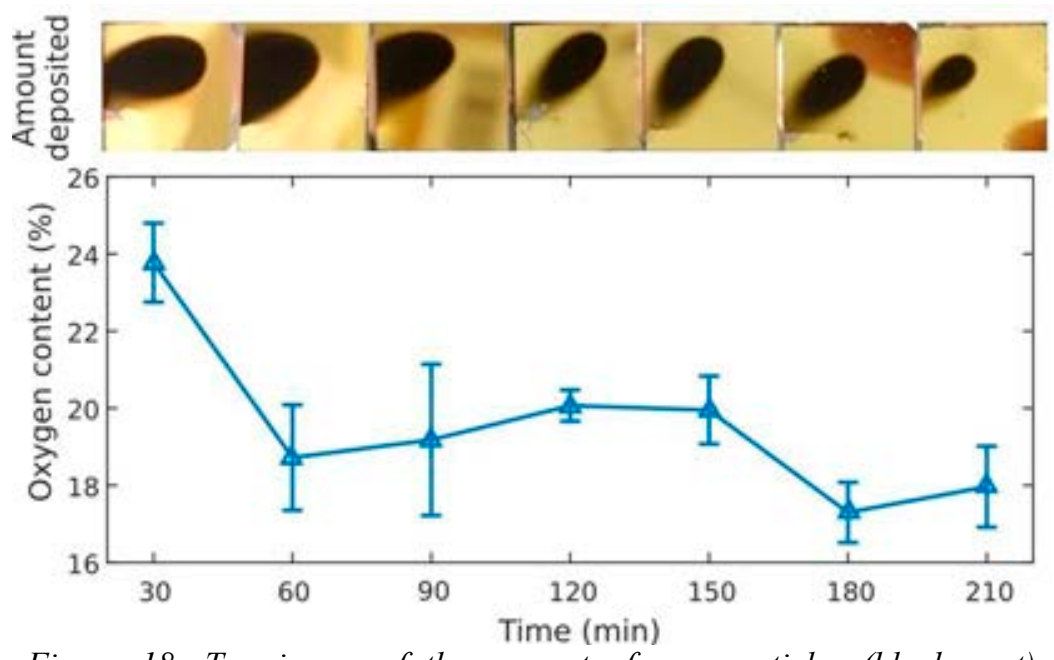

Figure 18: Top image of the amount of nanoparticles (black spot) deposited on the gold substrates after 30 minutes of deposition for up to 210 minutes of total process time. A decrease in the spot size as a function of time can be seen. EDX measurements of the particles oxygen content on the corresponding substrates. A decrease in the oxygen content can be seen as a function of time. The error bars show the standard deviation from the measurement at different positions on the substrate. The experiments were performed in high vacuum.

The decrease in deposition rate is a common behavior in cluster sources and has previously been reported for cobalt [47] tungsten [50] silver [67] and titanium [65]. The explanation for this behavior is that the residual gas consisting mainly of water vapor aids in the nucleation process of the particles, and thus when this gas gets depleted over time, less particles get created. When low enough base pressures were reached, the nucleation stopped and no particles were found on the substrate. Attempts were made to add an external supply of oxygen to stabilize the deposition rate, but this approach removes the possibility to make particles with a low oxygen content. The lack of control causes challenges when the process is to be applied for devices that require an even amount of particles and a controlled low oxygen content.

The second problem that was encountered was the contamination issue of oxygen within nanoparticles when other material systems were attempted. By adding nitrogen gas to the sputtering process, the goal was to produce titanium nitride nanoparticles for abrasive applications where high hardness and sharp edges on the nanoparticles were desired. 


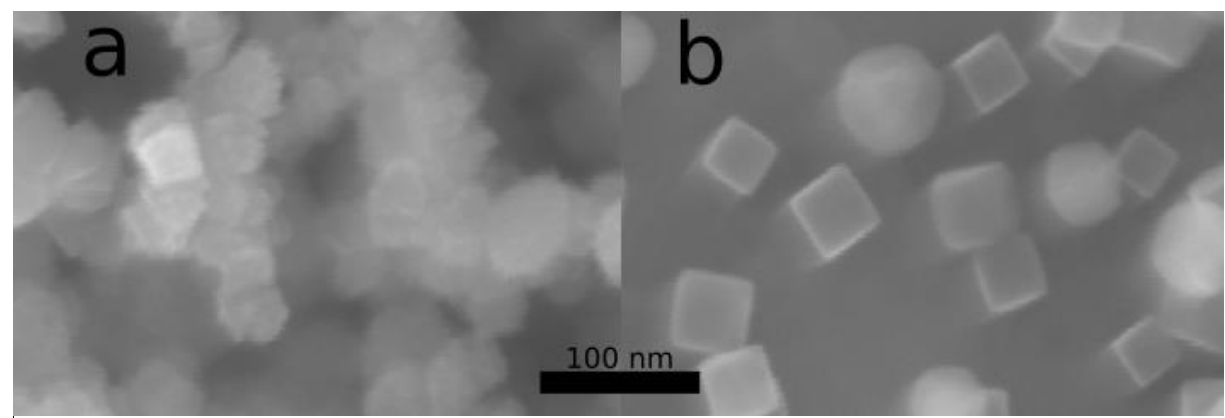

Figure 19: attempts to synthesize titanium nitride nanoparticles. At a higher base pressure the nanoparticles gets an irregular shape due to the high oxygen content (a). If the base pressure is lower, it is possible to synthesize cubic shaped titanium nitride nanoparticles with a lower oxygen content (b).

This requirement could not be fulfilled at a base pressure of $1.46 \cdot 10^{-4} \mathrm{~Pa}$ as can be seen in Figure. 19 (a). The particles got an irregular cauliflower shape and the EDX measurements approximate the average particle consists of $18 \%$ oxygen, $47 \%$ nitrogen and $35 \%$ titanium. If the base pressure was decreased to $1 \cdot 10^{-4} \mathrm{~Pa}$, the particles shape changed significantly as can be seen in (b). This was done by depositing titanium on the vacuum chamber wall while opening the throttle valve to increase the effective pumping speed prior to the experiment. After this, the nanoparticles showed a significantly lower oxygen content of only $3 \%$. The nitrogen content was $57 \%$ and the titanium content was $40 \%$. However, by decreasing the base pressure, the deposition rate decreased, which indicates that oxygen was required to nucleate the particles even when nitrogen was present. In addition to this, the base pressure would continue to drift during and between depositions, influencing the particle shape and composition. It is thus not feasible to make high purity nitrides in high vacuum.

The last example of this residual gas issue, was the attempt to make indium aluminum nitride nanoparticles for semi conducting applications. The basic idea was to tune the band gap by changing the aluminum content of the nanoparticles. To do this, a separate aluminum cathode was placed under the hollow cathode as can be seen in Figure. 20 (a). The cylindrical shaped cathode was $6 \mathrm{~mm}$ long with an internal diameter of $15 \mathrm{~mm}$ and was operated in DC mode. 

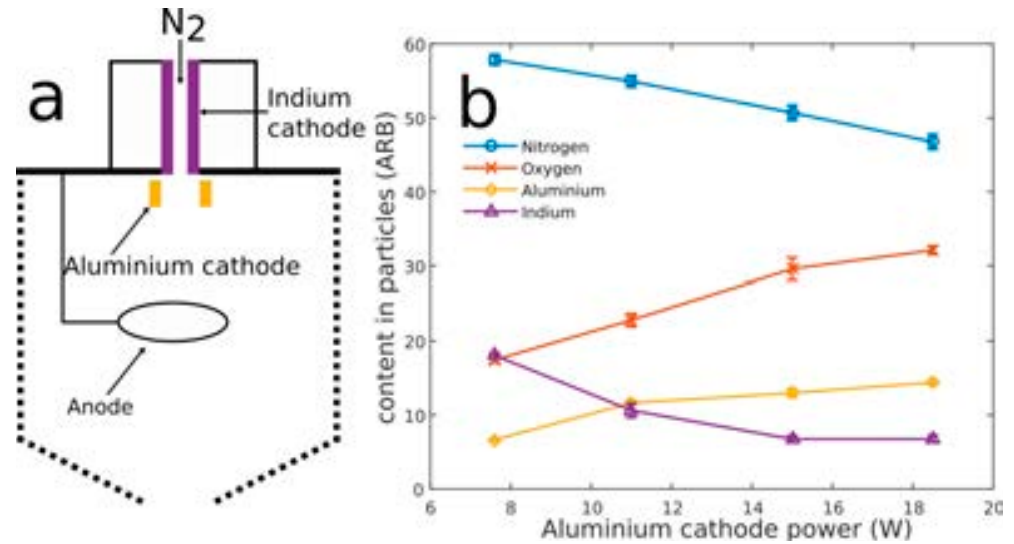

Figure 20: (a) The experimental setup used for synthesizing indium aluminium nitride nanoparticles A regular hollow cathode made out of indium was used with a separate cylinder shaped aluminium cathode underneath. (b) EDX analysis of the nanoparticle composition as a function of the aluminium cathode power. The error bars show the standard deviation between measurements on the same sample. The aluminium and oxygen content increases with increasing aluminium cathode power.

From the EDX measurements of the resulting nanoparticles it is clear that it is possible to tune the aluminium content of the nanoparticles by increasing the power to the aluminium cathode. But what is also seen is that there is a significant amount of oxygen within the nanoparticles that increases with increasing aluminium cathode power. This is most likely because the aluminium's high reactivity with oxygen in combination with that the cathode heats up at higher discharge powers, which causes it to degas more water vapour. Since the oxygen content will also influence the nanoparticles semiconducting properties, tuning the band gap by changing the aluminium content did not work.

It is thus concluded that synthesizing pure nanoparticles of highly reactive materials such as titanium or aluminum in high vacuum is not practically feasible if purity, reproducibility or a controlled deposition rate is necessary. The question that was asked at this stage of my research was "how is it possible to nucleate titanium nanoparticles without contaminating them with oxygen?" The next section is devoted to answer this question. 


\subsection{The growth of nanoparticles without oxygen}

For the purpose of studying nucleation, the ultrahigh vacuum system shown in Figure. 5 was build. This section will present the experimental results obtained from this equipment and compare them to the observations made earlier in high vacuum. Many experiments were performed before parameters that could produce nanoparticles at ultrahigh vacuum base pressures were found. Combinations of high argon gas pressures and high peak current values were attempted without any success. It was when helium was added, the gas pressure was increased, and the argon gas flow was decreased that nanoparticles could be found. The following section will show the process window where this is possible and how the process parameters influence the nanoparticles growth environment

\subsubsection{The process window}

A constant helium gas flow of $55 \mathrm{sccm}$ was injected separate to the argon gas flow into the experimental setup (Figure. 5). The appearance of nanoparticles on the substrates was investigated in a 2-d parameter space of pressure and argon gas flow. The resulting process window can be seen in Figure. 21

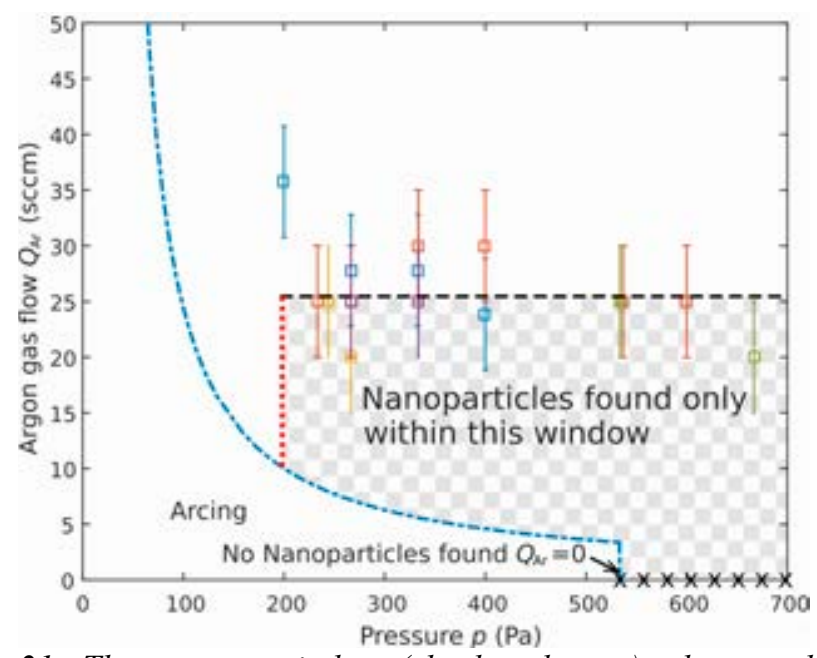

Figure 21: The process window (checkered area) when synthesizing nanoparticles in ultrahigh vacuum. The data points with the error bars represents the highest possible argon gas flow where nanoparticles were observed. The black dashed line is fitted to these data points. No nanoparticles were observed at pressures lower than the red dotted line or if there was no argon gas flow (crosses). The discharge became unstable below the blue dot-dashed line. 
The dashed black line represents the average argon gas flow over which no nanoparticles were found. The red dotted line represents the pressure below which no nanoparticles were found. The blue dot dashed line represents the lowest possible argon gas flow that could be used without the process starting to arc. The reason for this lower limit is discussed in paper 3 . The different lines create a process window (checkered area) where one has to operate in ultrahigh vacuum to obtain nanoparticles. It was attempted to synthesize nanoparticles without helium inside this window, but no particles were found. In paper 3 it is shown that the addition of oxygen to the helium gas flow allowed nanoparticles to be synthesized at higher argon gas flows, effectively increasing the size of the process window. This raised the question whether the lack of oxygen was the reason for the upper process limit (black dashed line). To answer this, we plot the process window in the high vacuum system and compare it to the observations in the ultrahigh vacuum system in Figure. 22.

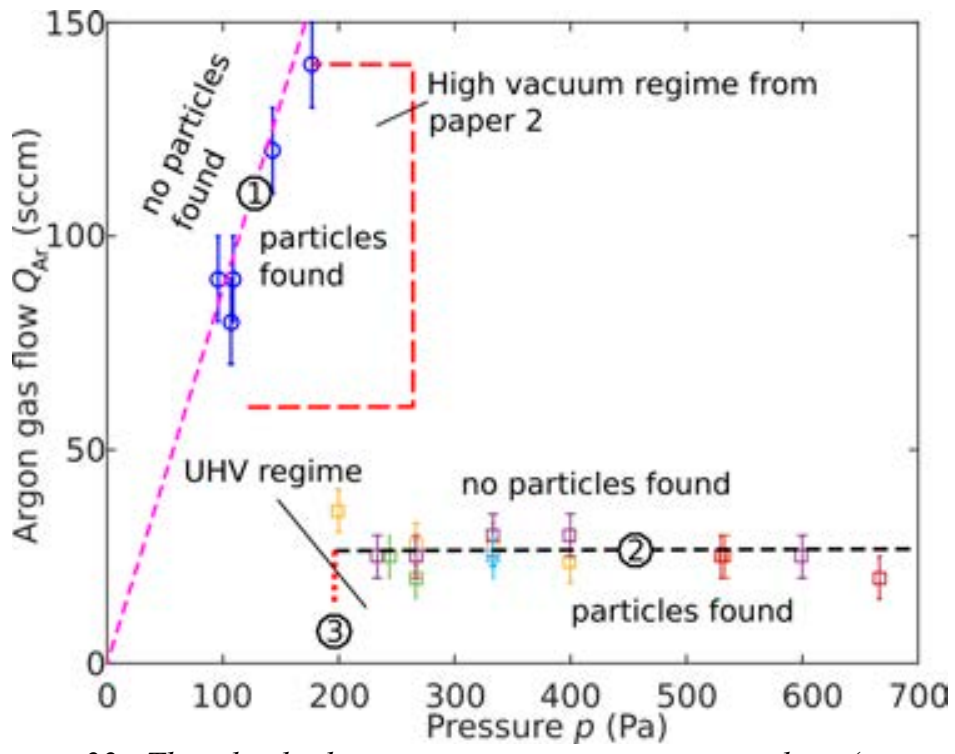

Figure 22: The ultrahigh vacuum systems process window (paper 3) compared to the one found in high vacuum (paper 2). The red dashed line represents the region investigated in paper 2. The limit of not finding nanoparticles in high vacuum (pink dashed line 1) has a slope which corresponds to a constant pressure/(argon flow) ratio. There is no such slope in the UHV regime (black dashed line 2).

In the high vacuum regime it was found that the nucleation with the aid of oxygen occurs below the pink dashed line. The explanation for this in paper 2 was that above the pink dashed line, the partial pressure of residual gas $p_{\mathrm{ox}}$ is too low. In this reasoning a constant supply of reactive gas from the growth tube walls $Q_{\mathrm{ox}}$ is assumed. When the gas flow $Q_{\mathrm{Ar}}$ is increased, the reactive gases 
get more diluted. The pressure $p_{\mathrm{Ar}}$ is increased by reducing the pumping speed, and thus the pumping speed that removes reactive gases from the growth tube becomes reduced. This gives us the relationship:

$$
p_{\mathrm{ox}} \propto Q_{\mathrm{ox}} \frac{p_{\mathrm{Ar}}}{Q_{\mathrm{Ar}}}
$$

This is why we see a slope in the pink dashed line. No such slope could be found in the black dashed line from the ultrahigh vacuum experiments. Thus there has to be a different process that limits the nucleation other than the partial pressure of reactive gases.

The following section will present the nucleation theory necessary to explain the limit of the black dashed line (2). It will be shown that it is due to a gas temperature increase when the argon gas flow is increased. At a certain threshold, the temperature will be too high for nanoparticles of pure titanium to nucleate. The reason the process window gets larger when oxygen is added is because oxidized nanoparticles are more stable at higher temperatures.

\subsubsection{Nucleation model}

Hybrid density functional theory was utilized in paper 4 to get the binding energy of adding titanium or oxygen atoms to a cluster. The results are presented in figure. 23 . 


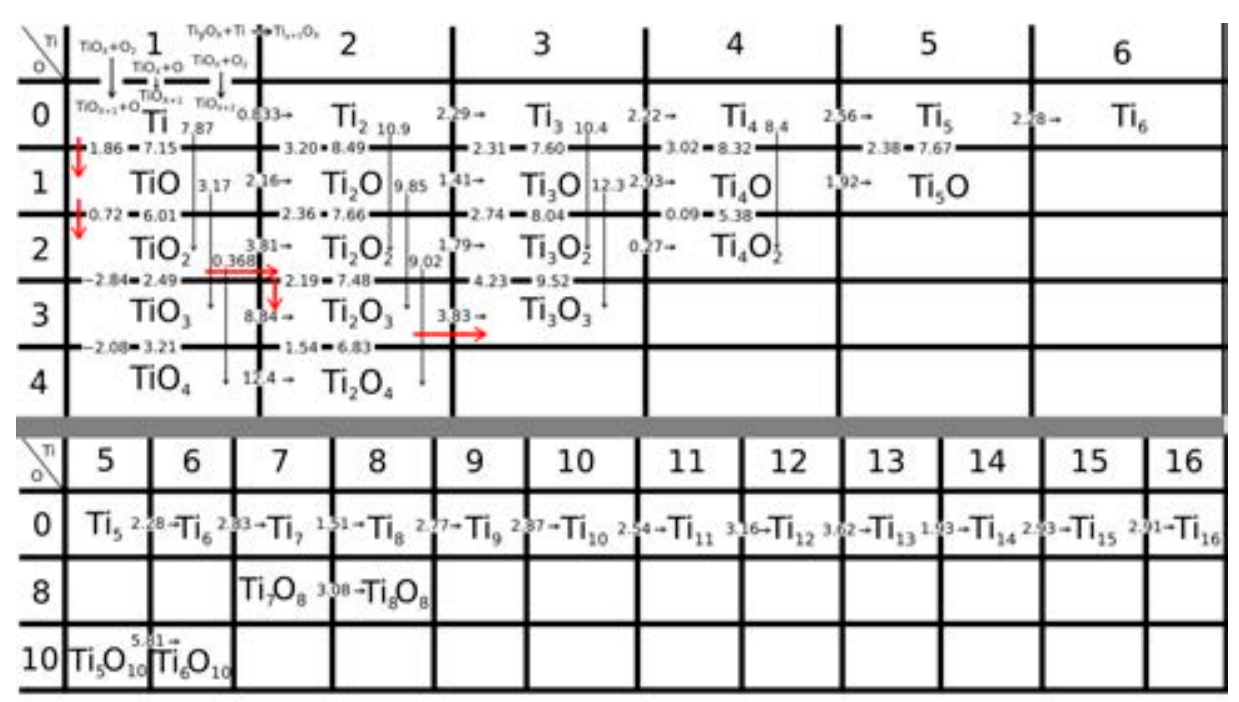

Figure 23: Binding energy when adding a titanium atom (arrow to the right). Binding energy when adding an oxygen atom (down). Energy released when adding an oxygen molecule (two cells down long arrow). Net energy released when adding an oxygen molecule followed by evaporation of one oxygen atom (left down corner of each cell). The red arrow denote the path of highest binding energy in an oxygen rich environment.

It can be seen that the energy released, and thus the binding energy of pure titanium clusters is lower compared to oxidized clusters. The most obvious such example is $\mathrm{Ti}_{2}$ which was found to have a binding energy of $0.833 \mathrm{eV}$ compared to $\mathrm{TiO}$ with a binding energy of $7.15 \mathrm{eV}$. This means that titanium clusters are easier to dissociate at elevated temperatures compared to titanium oxide clusters. In addition to this, growth by oxygen molecules allow for the following type of reactions to occur:

$$
\mathrm{TiO}+\mathrm{O}_{2} \rightarrow \mathrm{TiO}_{3}^{\ddagger} \rightarrow \mathrm{TiO}_{2}+\mathrm{O}
$$

Where a hot cluster can cool down by releasing one atom from the oxygen molecule. In this case there is no risk of dissociation of the the $\mathrm{TiO}_{2}$ cluster because the energy that gets transferred to heat is only $0.72 \mathrm{eV}$, which is less than its binding energy. In paper 4 it is argued that the path of the red arrows in figure. 23 is the most common growth path in an oxygen rich environment, since it minimizes the net evaporation rate from the cluster.

The question that still needs to be answered is how a clusters evaporation rate is related to the gas temperature and the binding energy. It was realized that the condensation of an atom on a cluster which gave a high binding energy would 
also heat it more compared to a condensation with a low binding energy. The cluster temperature after an atom has condensed was estimated to be

$$
T_{\mathrm{NP}} \approx T_{\mathrm{g}}+\frac{E_{\text {evap }}}{\vartheta k_{\mathrm{B}} N}
$$

Where $T_{\mathrm{g}}$ is the temperature the cluster had before the condensation event, which is most likely the gas temperature, $E_{\text {evap }}$ is the energy released from the condensation, $N$ is the number of atoms in the cluster and $\vartheta$ is the specific heat capacity per atom which was approximated to be the same as the bulk value (3.16). Assuming an isolated $\mathrm{Ti}_{3}$ cluster in a prefect vacuum $\left(T_{\mathrm{g}}=0\right)$ on which a titanium atom condenses, creating a $\mathrm{Ti}_{4}$ cluster it obtains a thermal energy of $2038 \mathrm{~K}$. If the temperature is decreased under this value, there is not enough internal energy to split it apart. Comparing this to bulk titanium at the same temperature, it would have a vapour pressure as high as $1.6 \mathrm{~Pa}$ [13]. The reason why a bulk object has a non-zero vapour pressure is that more total energy can be stored in it at a given temperature. Thus it becomes statistically possible for atoms to obtain enough energy to overcome the binding energy even at low temperatures. This would also be true for small clusters submerged in a hot gas of similar temperatures. Statistically it then becomes possible for the cluster to collide with a gas atom that has enough energy to heat the cluster over a temperature where it evaporates. This is however not the case in this experimental setup since the growing clusters would have a significantly higher temperature than the gas, making these high energetic collisions un-likely.

From this realization a new model for cluster evaporation was introduced in paper 4 where the evaporation rate was zero below this critical temperature, and only possible in a small window after the condensation of an atom on the cluster. The model is illustrated in figure 24 


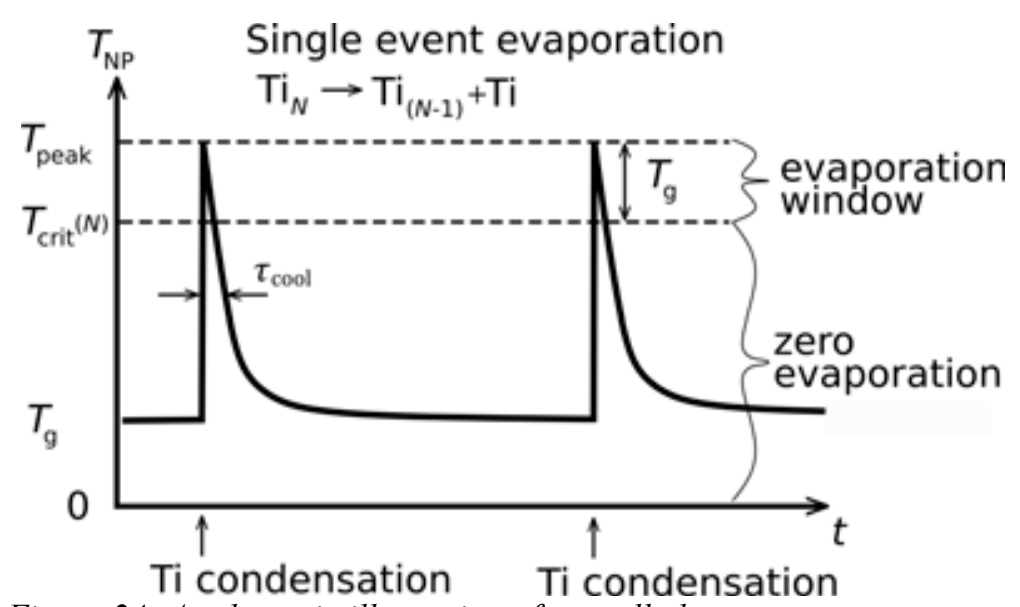

Figure 24: A schematic illustration of a small clusters temperature as a function of time. The evaporation window is only as high as the gas temperature.

A cluster will first have the same temperature as the gas $T_{\mathrm{g}}$. When a titanium atom condenses on the cluster, it obtains the binding energy plus the gas temperature (equation 26). The cluster now has enough internal energy to evaporate. Inside this evaporation window, there is a finite probability that one atom on the cluster gets enough energy to overcome the binding energy. Statistically it could also cool down below $T_{\text {crit }}(N)$ before this happens. Once it has cooled down, it can condense a new atom, and the process repeats itself. Inside the evaporation window, the vapour pressure has an exponential temperature dependence

$$
p_{\text {vap }} \propto \exp \left(-\frac{E_{\text {evap }}}{k_{\mathrm{B}} T_{\mathrm{NP}}}\right)
$$

And thus, the evaporation probability should also have an exponential temperature dependence. It is here the process gas temperature becomes important for nanoparticles to reach their thermodynamically stable size, since the height of the evaporation window is an equal amount of degrees kelvin as the gas temperature. An exponential increase of the evaporation rate in combination with large amounts of condensation steps necessary to reach the nanoparticles' thermodynamically stable size, result in a very strong temperature dependence. A gas temperature increase at higher argon gas flows explains the limit where no nanoparticles were found marked 2 in Figure. 22. 


\subsubsection{The experimental parameters influence on the growth environment.}

The pressure and the argon gas flow are the main parameters that were varied in the ultrahigh vacuum system. We will here look deeper in to how these parameters will influence the internal parameters that govern the processes which allows for nanoparticles to grow.

In the UHV system (Figure. 5) there are two separate inlets for the process gas. The inlet for argon passes through the hollow cathode before entering the growth zone while the helium is injected under a copper gasket. This means that the argon gas will have the same temperature as the hollow cathode wall, which would be in the order of $1000 \mathrm{~K}$ [68] to $1500 \mathrm{~K}$ [43]. This temperature will have to be cooled down inside the growth zone by thermal conduction through the helium-argon gas mixture. An increase in the argon gas mass flow would increase the amount of gas that obtains this high temperature, and thus a hot zone will extend further out from the hollow cathode. In addition to this, it will also decrease the fraction of helium inside the growth zone, and thus decrease the thermal conductivity of the gas mixture [69], which will further increase the extension of this hot zone. The argon gas flow will thus influence the temperature $T_{\mathrm{g}}$ of the background gas in which the nanoparticles nucleate.

The pressure will to a first approximation not influence the gas temperature. It will however increase the gas density $n_{\mathrm{g}}$ and there by increase cooling rate of a nanoparticle due to the higher collision rate with the colder process gas atoms [55]. A higher pressure will also decrease the diffusion rate of the sputtered titanium flux, giving them a higher density. An overview of the parameters and processes that govern whether nanoparticles are found on the substrate or not can be seen in Figure. 25 


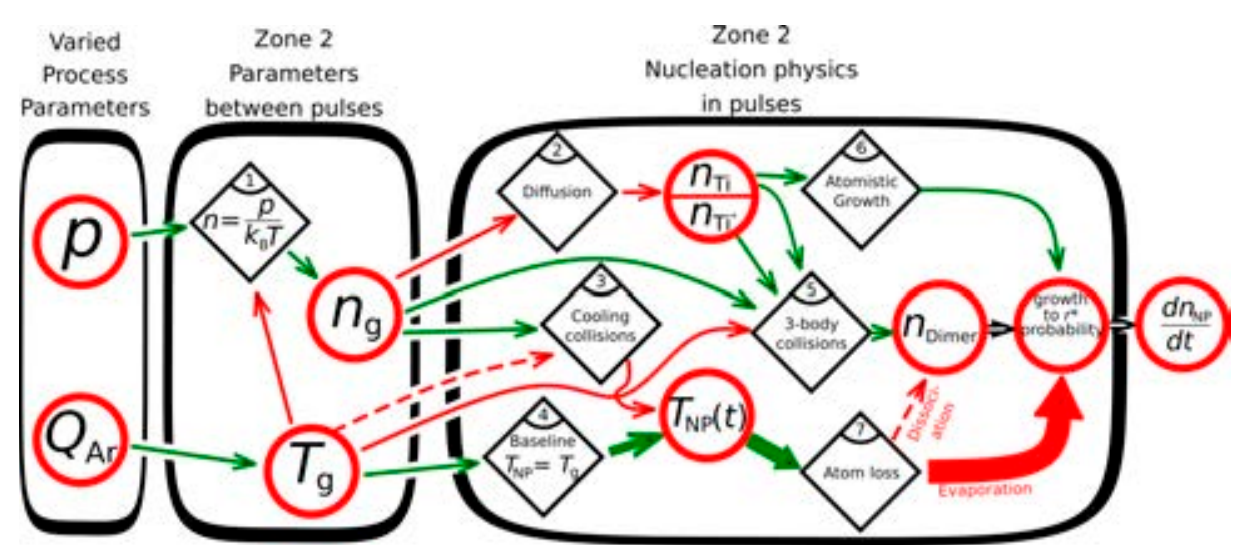

Figure 25: The different parameters (circles) and processes (diamonds) that influences the nucleation rate. A green arrow indicates that an increase in one process/parameter leads to an increase in another. A red arrow indicates a decrease. Thick arrows indicate a strong increase/decrease.

The pressure $p$ and argon gas flow $Q_{\mathrm{Ar}}$ were the varied external parameters. An increasing pressure would increase the gas density $n_{\mathrm{g}}$ due to the ideal gas law (process 1), while the argon gas flow increases the gas temperature $T_{\mathrm{g}}$ as discussed. These two internal parameters will influence the nucleation physics. Starting with the gas temperature, $T_{\mathrm{g}}$. An increasing gas temperature decreases the gas cooling rate by collisions on a growing nanoparticle (process 3), decreases the amount of 3-body collisions (process 5) and increases the nanoparticles baseline temperature (process 4). This results in warmer clusters and less dimers from which nanoparticles can grow. The nanoparticle temperature $T_{\mathrm{NP}}(t)$ will strongly influence the atom loss rate (process 7) and the dissociation of dimers, which strongly governs the probability of a sub critical cluster to grow to its thermodynamically stable size $r^{*}$. An increased gas density, $n_{\mathrm{g}}$ will decrease the diffusion rate (process 2 ) of the sputtered species. It will also increase the 3-body collision rate (process 5) and the cooling rate of the nanoparticles. The decreased diffusion rate increases the titanium neutral $n_{\mathrm{Ti}}$ and ion $n_{\mathrm{Ti}^{+}}$density, which both increases the 3-body collision rate (process 5) and the atomistic growth rate (process 6). These steps increase the amount of dimers created and the probability of a titanium cluster to grow to its thermodynamically stable size $r^{*}$. This explains the red dotted line in Figure. 22. At a certain threshold pressure, all of these processes combined gives too few nanoparticles to be detected on the substrates. 


\section{6 applying the process to manufacture devices}

A separate goal with this work was to demonstrate that this process is feasible for practical applications. In this section examples of how it was applied to manufacture devices is presented. First the use of molybdenum nanoparticles in copper indium gallium selenide (CIGS) solar cells will be demonstrated. Then the use of titanium dioxide nanoparticles to functionalize graphene based gas sensors will be shown.

\subsubsection{Solar cells with molybdenum particles}

A way to reduce the cost of manufacture CIGS solar cells is to decrease their thickness. This reduces the amount of the expensive indium and gallium required as well as the time it takes to manufacture each cell. As the thickness becomes less than $500 \mathrm{~nm}$, the efficiency significantly decreases. One reason for this is the low internal reflection between the CIGS layer and the material it is deposited on (in this case a molybdenum thin film). The idea of this work was to scatter the incoming light on molybdenum particles embedded inside the CIGS layer, effectively increasing the distance the light travels in the solar cell [70]. The requirement specification for this to function was a monolayer of particles with a size in the order of $150-200 \mathrm{~nm}$ that are also well separated from each other. By tuning the process parameters, particles with the desired size was possible to obtain.

The process parameters used was: $750 \mathrm{~Hz}$ frequency, $80 \mu$ s pulse width, $271 \mathrm{~V}$ pulse voltage, peak currents in the order of $4 \mathrm{~A}$, mesh bias of $-50 \mathrm{~V}$, pressure of $110 \mathrm{~Pa}$, argon gas flow of $5 \mathrm{sccm}$ and an oxygen gas flow of $0.025 \mathrm{sccm}$. It was also found that the dispersion of the nanoparticles on the substrate was determined by the potential of the substrate. If a positive substrate bias was used, the particles had a higher tendency to agglomerate (stick together) on the substrate as can be seen in Figure. 26 (b). If the substrates had a floating potential, there was a much better dispersion on the substrates (a). 


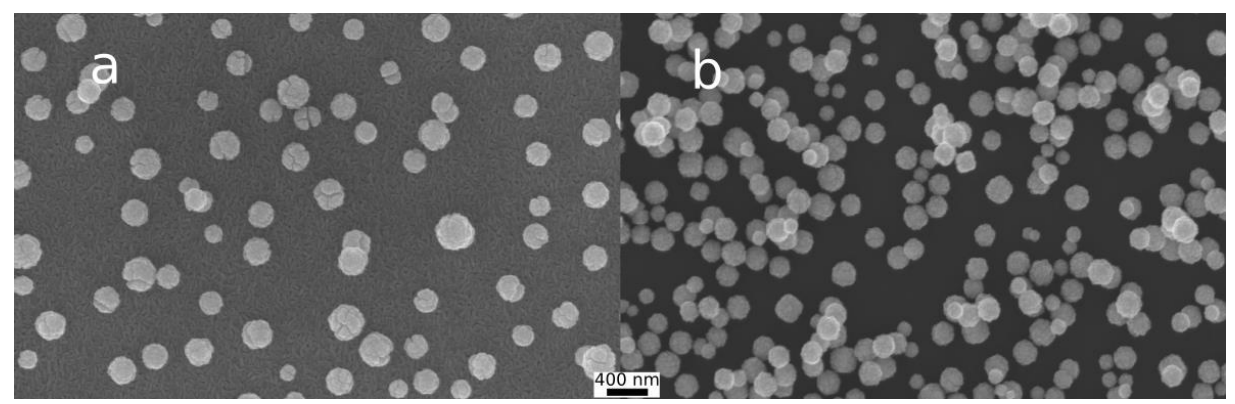

Figure 26: nanoparticles of molybdenum deposited with a floating substrate potential (a), deposited with a positive substrate bias of $25 \mathrm{~V}$ (b). The particles are better dispersed with a floating substrate potential.

An explanation for this is that the substrate charges up slightly negative due to the flux of negatively charged particles. They then act an electric field concentration points which repel other incoming particles. The reverse will be true if a positive substrate bias is used. The particles will then attract other negatively charged particles due to their concentrated positive field. A floating substrate also appeared to be self-regulating, where a monolayer could quickly be deposited, but after that the amount of particles deposited on the substrate per unit of time decreased.

The particles were deposited on glass substrates coated with a molybdenum thin film. The rest of the CIGS solar cell was then deposited on top of this. A cross sectional SEM image can be seen in Figure. 27 of a finished solar cell with molybdenum particles embedded inside.

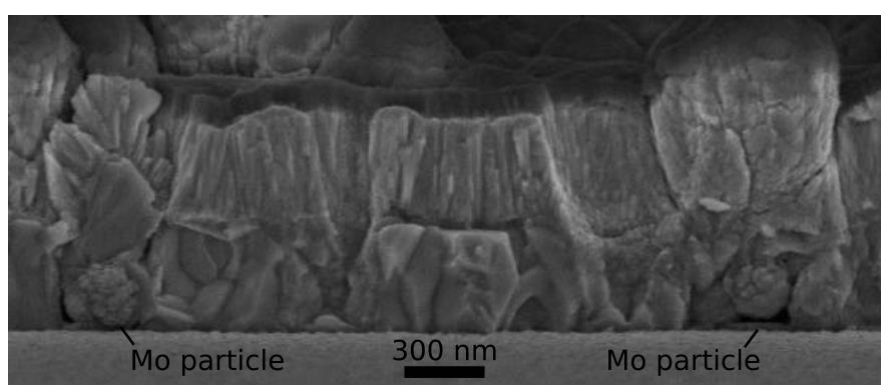

Figure 27: cross sectional SEM image of a CIGS solar cell with molybdenum particles embedded inside.

The addition of the particles increased the short circuit current of the solar cells, as were expected if they had a light scattering effect. However, the open circuit voltage decreased. Over all, the addition of molybdenum particles (and a thin $\mathrm{Al}_{2} \mathrm{O}_{3}$ passivation layer) increased the cells average efficiency from $8.4 \pm 1.3$ to 
$8.8 \pm 0.8 \%$ [70]. This shows the feasibility of applying this technique to photovoltaic applications.

\subsubsection{Graphene based gas sensors.}

Toxic volatile organic compounds (VOCs) are gases that can be present in normal living environments. Since we spend much of our time indoors, the dose accumulated from parts per billion levels can be toxic. This increases the demand for high sensitivity sensors that can detect these low concentrations. Graphene based gas sensors show promise for a high sensitivity, but often lack the ability to distinguish which gases it is reacting to (low selectivity). The idea of this work was to increase the selectivity by adding titanium dioxide nanoparticles on top of the graphene layer. One concern was whether this would damage the graphene layer, which had been observed when growing metal islands on top of the graphene layer by conventional magnetron sputtering [71].

The process parameters used was: $1500 \mathrm{~Hz}$ frequency, $80 \mu$ s pulse width, 302 $\mathrm{V}$ pulse voltage, peak currents in the order of $12 \mathrm{~A}$, pressure of $110 \mathrm{~Pa}$, argon gas flow of $103 \mathrm{sccm}$. To get titanium dioxide, an oxygen gas flow of $0.25 \mathrm{sccm}$ was used. Nanoparticles of two different size distributions were deposited on substrates made out of epitaxial graphene grown on silicon carbide. To tune the size without influencing the particle oxygen content, a mesh bias of $-50 \mathrm{~V}$ was used to obtain $50 \mathrm{~nm}$ particles and a mesh bias of -10 was used to obtain $\leq 10$ $\mathrm{nm}$ particles. It was possible to deposit the larger nanoparticles with a floating substrate bias, and thus obtain a good dispersion as can be seen in Figure. 28 (a). A substrate bias was however required to collcect the small $\leq 10 \mathrm{~nm}$ particles (b) and a bias of $40 \mathrm{~V}$ was used.

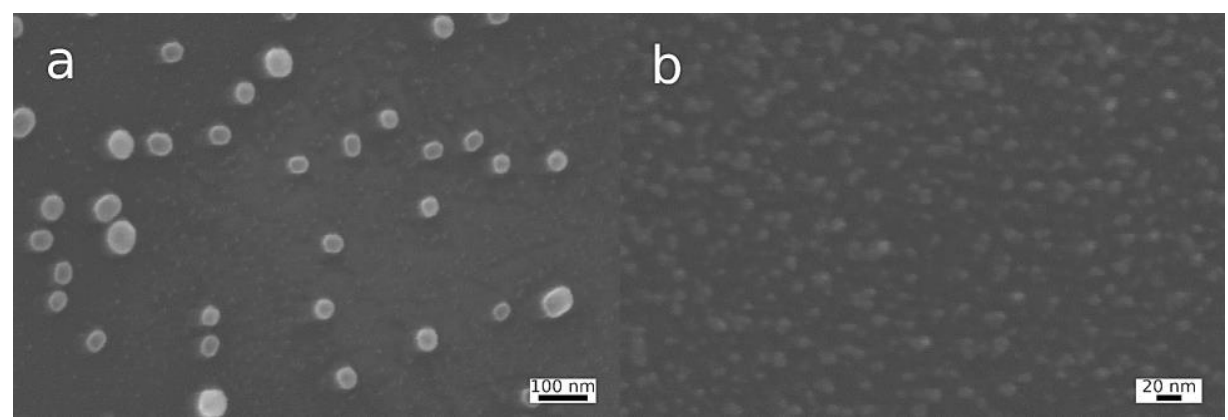

Figure 28: Nanoparticles of titanium dioxide deposited on graphene. (a) A mesh bias of $-50 \mathrm{~V}$ and a floating substrate bias gave nanoparticles with good dispersion and with a size in the order of $50 \mathrm{~nm}$. (b) A mesh bias of-10 V deposited particles with a size of $<10 \mathrm{~nm}$. 
Raman spectroscopy could not detect any damage to the graphene from the deposition of the nanoparticles, however a small shift in the $G$ peak was observed which might be due to doping from the addition of the titanium dioxide. Three common VOCs were tested on the sensors: formaldehyde, naftalene and benzene. It was found that the sensors selectivity depended on the size of the nanoparticles. The sample with $\leq 10 \mathrm{~nm}$ particles was selective towards formaldehyde while the $50 \mathrm{~nm}$ particles were selective towards benzene [71]. These results show that by applying the insights from paper 1, this nanoparticle synthesis process can be used to tune the properties of graphene. 



\section{Contributions to the field}

Paper 1 shows that the combination of pulsed sputtering and a hollow cathode with an inert gas flow through allows for stable reactive sputtering conditions. This stability makes it possible to tune the nanoparticle oxygen stoichiometry. It was also found that the nanoparticle size could be changed without influencing the particle oxygen content, which had previously not been reported for similar experimental setups. This opens up the possibility to optimize these two particle properties for future technological applications.

Conflicting results had been found in the literature regarding whether gas flow and pressure have a size increasing or decreasing effect [40] [38] [61]. Usually in Haberland type cluster sources, the pressure is set by the argon gas flow, making it hard to distinguish the two parameters from each other. Due to the design of the experimental setup used in paper 2, it was possible to study their effect independently from each other. It was found that the pressure increased the nanoparticles size faster than linear. The reason for this was a decrease in the ambipolar diffusion rate of the growth material in combination with a longer residence time of fast ejected particles at higher pressure. The effect on the nanoparticle size by varying the argon gas flow was found to be dependent on the pressure. At pressures lower than $177 \mathrm{~Pa}$, there was a size decrease with increasing argon gas flow. At pressures higher than $177 \mathrm{~Pa}$, the trend was the opposite. This could help explain the conflicting results in the literature. The morphology of the nanoparticles was also found to be controllable with the pressure. The transition from spherical/weakly faceted to cubic with a fractured surface evolving to cauliflower shaped nanoparticles could be closely studied as a function of increasing pressure. This made it clear that it was a low ad atom mobility during the surface growth stage that caused the cauliflower morphology, which is different from previous explanations of similar structures, where the shape was explained to originate from the agglomeration of $3 \mathrm{~nm}$ particles [50]. The ability to control the morphology opens up possibilities to tune particles with properties suitable for photoelectric and photocatalytic applications [72] [73]. Paper 2 also confirmed the observation that a partial pressure of oxygen or water vapor is necessary to grow nanoparticles of titanium at typical cluster source operating conditions [48] [65] [47]. A link between partial pressure of oxygen, argon gas flow and pressure was established. It also highlights the problem of not being able to make pure titanium nanoparticles, since the nucleation stopped before a low enough partial pressures of oxygen for non-contaminated nanoparticles to grow was reached. 
This problem was solved in paper 3 where growth of pure titanium nanoparticles was shown to be possible without the need to externally add oxygen. It was found that this can be done by increasing the pressure and decreasing the temperature of the nanoparticles growth environment. One reason that this had not previously been studied could be that other cluster sources that utilizes sputtering typically uses magnetrons that are not designed to operate at higher pressures [28]. This paper shows that one can simply modify a magnetron by substituting the ground shield for a fiberglass weave, attaching a hollow cathode clamped to a copper block on it and thus operate in this region. The function of helium was to decrease the temperature of the gases ejected from the hollow cathode. An increasing helium flow was also found to decrease the nanoparticle size. A process window where the nucleation and growth is possible is presented. The results of this paper highlights that nucleating nanoparticles by this mean is a better approach than relying on the base pressure to supply the nucleation seeds, since it would allow for cleaner particles and a more stable process.

In paper 4 we present a new explanation for the evaporation behavior of small clusters, where they have to be above a critical temperature in order to evaporate. Under this critical nanoparticle temperature, the evaporation rate is zero. This lay the foundation of explaining the first stages of nucleation of clusters with a smaller size than what is usually thermodynamically modeled. Previously published works on the growth of titanium nanoparticles in a gas aggregation sputter source have suggested that it is the binding energy of the dimers which determine whether nanoparticles nucleate or not [48] [65] [47]. In our experimental setup, we show that it is the binding energy of the growing clusters that is the determining factor. In addition to this, the oxygen molecule can split apart when binding to a growing titanium cluster, and thus prevent it from acquiring a high enough energy to evaporate. This can be translated to other people in the field who have a relative high temperature in their cluster sources. The conclusion of this is that the temperature has to be decreased in order to grow nanoparticles without oxygen contaminations. The calculations show that ions can significantly enhance the 3 -body collision rate and that dimer formation is possible with a 2-body collision between a titanium ion and an oxygen molecule. The ability to form dimers by 2-body collisions is not often considered [40] [38]. We thus suggest that it is possible to grow titanium nanoparticles without the need to externally supply contaminants such as oxygen or water vapor. However we cannot rule out that 2-body collisions with water molecules did play a significant role for the dimer formation in our experiments. 


\section{Future outlook}

To continue where I left of, I would first recommend to optimize the process window from Paper 3 with regards to deposition rate and nanoparticle size distribution. This could be done by tuning the helium gas flow and optimizing the discharge parameters such as frequency, peak current and pulse widths. It would be commercially valuable to see if the same productivity as sometimes occurs with oxygen can be achieved with helium as well, but in a controlled manner. Once an efficient and stable process is mastered, it is possible to start making advanced nanoparticles. One such example is to continue the work with titanium aluminum nitride which is now feasible without getting contamination. Another experiment that was attempted but not reported on here was to coat nanoparticles with a different material. This work could not continue because the control and understanding of the process supplying the core particles was at the time lacking, but preliminary results showed that by placing an inverted magnetron below the growth zone, a coating of a different material could be deposited in the particle surface.

Many applications require the nanoparticles to be deposited glass substrates, which was found to be difficult to do with this technique. It would probably be possible by putting a small aperture after the growth zone and differentially pump the substrate table to a lower pressure. This would accelerate the particles, giving them a high enough velocity to overcome the repulsive charge build up on the glass substrates.

On the theory aspects, it would be interesting to attach a mass spectrometer to probe the density of dimers and clusters in the plasma. This could give answers about which clusters that are more prominent and how oxygen interacts with the initial dimer formation. The intensity of $\mathrm{Ti}_{2}$ and $\mathrm{TiO}$ dimers as a function of base pressure and process pressure would give experimental verification of the theory proposed about dimer formation. This is important because if oxygen is not a significant part of the nanoparticle nucleation and growth process, it is possible to have a stable deposition rate

The effect of the external parameters on the internal parameters could be modeled with finite element analysis. This will give a deeper insight of the distribution of temperature, velocity and helium within the growth zone. 


\section{References}

[1] W.J. Stark, P.R. Stoessel, W. Wohlleben, A. Hafner, Industrial applications of nanoparticles, Chem. Soc. Rev. 44 (2015) 5793-5805.

[2] X. Chen, S.S. Mao, Titanium dioxide nanomaterials: synthesis, properties, modifications, and applications., Chem. Rev. 107 (2007) 2891-959.

[3] P. Spinelli, V.E. Ferry, J. Van De Groep, M. Van Lare, M.A. Verschuuren, R.E.I. Schropp, et al., Plasmonic light trapping in thin-film Si solar cells, J. Opt. 14 (2012) 24002.

[4] A. Ghaderi, E.A. De Mayolo, H.K. Patra, M. Golabi, Keys and regulators of nanoscale theranostics, Adv. Mater. Lett. 6 (2015) 87-98.

[5] D.A. Links, New insight into the soot nanoparticles in a candle flame, Chem. Commun. 47 (2011) 4700-4702.

[6] A. Betke, G. Kickelbick, Bottom-Up, Wet Chemical Technique for the Continuous Synthesis of Inorganic Nanoparticles, Inorganics. 2 (2014) $1-15$.

[7] F. Kruis, H. Fissan, a Peled, Synthesis of nanoparticles in the gas phase for electronic, optical and magnetic applications - a review, J. Aerosol Sci. 29 (1998) 511-535.

[8] I. Pilch, D. erstr ,N. Brenning, U. Helmersson, Size-controlled growth of nanoparticles in a highly ionized pulsed plasma, Appl. Phys. Lett. 102 (2013) 33108.

[9] I. Pilch, D. str ,M.I. Hasan, U. Helmersson, N. Brenning, Fast growth of nanoparticles in a hollow cathode plasma through orbit motion limited ion collection, Appl. Phys. Lett. 103 (2013) 193108.

[10] J.F. O'Hanlon, A User's Guide to Vacuum Technology, 3rd Edition, Wiley-Interscience, 2003.

[11] A. Anders, J. Andersson, A. Ehiasarian, High power impulse magnetron sputtering: Current-voltage-time characteristics indicate the onset of sustained self-sputtering, J. Appl. Phys. 102 (2007) 113303.

[12] H.A. Jakobsen, Chemical Reactor Modeling: Multiphase Reactive Flows, Springer, 2008.

[13] C.B. Alcock, V.B. Itkin, M.K. Horrigan, Vapour Pressure Equations for the Metallic Elements: 298-2500K, Can. Metall. Q. 3 (1984).

[14] R.C. Krutenat, C. Panzera, Low - Energy Ar + Sputtering Yields of Solid and Liquid Tin Low-energy sputtering yields of tungsten and tantalum Low - Energy Sputtering Yields of Ge Single Crystals as a Function of Temperature, J. Appl. Phys. 41 (1970) 4953.

[15] Y. Yamamura, H. Tawara, Energy Dependence of Ion-induced Sputtering Yields From Monatomic Solids at Normal Incidence, At. DATA Nucl. DATA TABLES. 62 (1996) 149-253. 
[16] C. Steinbriichel, A Simple Formula for Low-Energy Sputtering Yields, Appl. Phys. A. 36 (1985) 37-42.

[17] M.I. Hasan, I. Pilch, D. Söderström, D. Lundin, U. Helmersson, N. Brenning, Modeling the extraction of sputtered metal from high power impulse hollow cathode discharges, Plasma Sources Sci. Technol. 22 (2013) 35006.

[18] H. Haberland, M. Karrais, M. Mall, Y. Thurner, Thin films from energetic cluster impact: A feasibility study, J. Vac. Sci. Technol. A. 10 (1992) 3266-3271.

[19] M. Ohring, The Material Science of Thin Films, Academic Press Limited, 1992.

[20] D. Depla, Magnetrons, reactive gases and sputtering, 2013.

[21] D. Söderström, Modelling and Applications of the Hollow Cathode Plasma, 2008.

[22] W.D. Sproul, D.J. Christie, D.C. Carter, Control of reactive sputtering processes, Thin Solid Films. 491 (2005) 1-17.

[23] T. Nyberg, S. Berg, U. Helmersson, K. Hartig, Eliminating the hysteresis effect for reactive sputtering processes, Appl. Phys. Lett. 86 (2005) 164106.

[24] M. Aiempanakit, T. Kubart, P. Larsson, K. Sarakinos, J. Jensen, U. Helmersson, Hysteresis and process stability in reactive high power impulse magnetron sputtering of metal oxides, Thin Solid Films. 519 (2011) 7779-7784.

[25] E. Wallin, U. Helmersson, Hysteresis-free reactive high power impulse magnetron sputtering, Thin Solid Films. 516 (2008) 6398-6401.

[26] T. Kalber, Gas flow sputtering of oxide coatings: practical aspects of the process, Surf. Coatings Technol. 86-87 (1996) 218-224.

[27] M. Aiempanakit, A. Aijaz, D. Lundin, U. Helmersson, T. Kubart, Understanding the discharge current behavior in reactive high power impulse magnetron sputtering of oxides, J. Appl. Phys. 113 (2013) 133302.

[28] K. Wegner, P. Piseri, H.V. Tafreshi, P. Milani, Cluster beam deposition : a tool for nanoscale science and technology, J. Phys. D Appl. Phys. 39 (2006) R439-R459.

[29] L. Mangolini, U. Kortshagen, Selective nanoparticle heating: Another form of nonequilibrium in dusty plasmas, Phys. Rev. E. 79 (2009) 26405.

[30] H. Factorovich, V. Molinero, A. Scherlis, Vapor Pressure of Water Nanodroplets, J. Am. Chem. Soc. 136 (2014) 4508-4514.

[31] V.M. Smirnov, Processes in expanding and condensing gases, PhysicsUspekhi. 37 (1994) 646.

[32] A.D. McNaught, A. Wilkinson, IUPAC. Compendium of Chemical Terminology, 2.3.3, IUPAC, 2014.

[33] M.A. Lieberman, A.J. Lichtenberg, Principles of Plasma Disharges and 
Materials Processing, Second Edi, Wiley, 2005.

[34] I. Shyjumon, M. Gopinadhan, C. a. Helm, B.M. Smirnov, R. Hippler, Deposition of titanium/titanium oxide clusters produced by magnetron sputtering, Thin Solid Films. 500 (2006) 41-51.

[35] S. Pratontep, S.J. Carroll, C. Xirouchaki, M. Streun, R.E. Palmer, S. Pratontep, et al., Size-selected cluster beam source based on radio frequency magnetron plasma sputtering and gas condensation, Rev. Sci. Instrum. 76 (2005) 45103.

[36] K.R. Bray, C.Q. Jiao, J.N. Decerbo, K.R. Bray, C.Q. Jiao, Influence of carrier gas on the nucleation and growth of $\mathrm{Nb}$ nanoclusters formed through plasma gas condensation, J. Vac. Sci. Technol. B. 32 (2014).

[37] T. Hihara, K. Sumiyama, Formation and size control of a Ni cluster by plasma gas condensation, J. Appl. Phys. 84 (1998) 1-8.

[38] A.I. Ayesh, H.A. Ahmed, F. Awwad, S. Abu-Eishah, S. Mahmod, Mechanisms of Ti nanocluster formation by inert gas condensation, J. Mater. Res. 28 (2013) 2622.

[39] E. Kesälä, a. Kuronen, K. Nordlund, Molecular dynamics simulation of pressure dependence of cluster growth in inert gas condensation, Phys. Rev. B. 75 (2007) 1-7.

[40] M. Drábik, A. Choukourov, A. Artemenko, J. Kousal, O. Polonskyi, P. Solař, et al., Morphology of Titanium Nanocluster Films Prepared by Gas Aggregation Cluster Source, Plasma Process. Polym. 8 (2011) 640650 .

[41] A. Marek, J. Valter, S. Kadlec, J. Vyskočil, Gas aggregation nanocluster source - Reactive sputter deposition of copper and titanium nanoclusters, Surf. Coatings Technol. 205 (2011) S573-S576.

[42] B. Smirnov, I. Shyjumon, R. Hippler, Flow of nanosize clustercontaining plasma in a magnetron discharge, Phys. Rev. E. 75 (2007) 19 .

[43] P. V. Kashtanov, B.M. Smirnov, R. Hippler, Efficiency of cluster generation in a magnetron discharge, EPL Europhys. Lett. 91 (2010) 63001.

[44] B.M. Smirnov, I. Shyjumon, R. Hippler, Formation of clusters through generation of free atoms, Inst. Phys. Publ. 73 (2006) 288-295.

[45] R.M. Nielsen, S. Murphy, C. Strebel, M. Johansson, I. Chorkendorff, J.H. Nielsen, The morphology of mass selected ruthenium nanoparticles from a magnetron-sputter gas-aggregation source, J. Nanoparticle Res. 12 (2010) 1249-1262.

[46] Y. Huttel, Gas-Phase Synthesis of Nanoparticles, 1st ed., wiley, Singapore, 2017.

[47] T. Peter, O. Polonskyi, B. Gojdka, A. Mohammad Ahadi, T. Strunskus, V. Zaporojtchenko, et al., Influence of reactive gas admixture on transition metal cluster nucleation in a gas aggregation cluster source, J. 
Appl. Phys. 112 (2012) 114321.

[48] A.M. Ahadi, V. Zaporojtchenko, T. Peter, O. Polonskyi, T. Strunskus, F. Faupel, Role of oxygen admixture in stabilizing TiO x nanoparticle deposition from a gas aggregation source, J. Nanoparticle Res. 15 (2013) 2125.

[49] O. Polonskyi, T. Peter, A. Mohammad Ahadi, A. Hinz, T. Strunskus, V. Zaporojtchenko, et al., Huge increase in gas phase nanoparticle generation by pulsed direct current sputtering in a reactive gas admixture, Appl. Phys. Lett. 103 (2013) 33118.

[50] T. Acsente, R.F. Negrea, L.C. Nistor, C. Logofatu, E. Matei, C. Grisolia, et al., Synthesis of flower-like tungsten nanoparticles by magnetron sputtering combined with gas aggregation, Eur. Phys. J. D. 69 (2015) 161.

[51] A. Bouchoule, Dusty Plasmas Physics, Chemistry and Technological Impacts in Plasma Processing, Wiley, 1999.

[52] A. Piel, Plasma Physics. An introduction to Laboratory, Space and Fusion Plasmas, Springer, 2010.

[53] A. Gallagher, Model of particle growth in silane discharges, Phys. Rev. E. 62 (2000) 2690-2706.

[54] L. Ravi, S.L. Girshick, Coagulation of nanoparticles in a plasma, Phys. Rev. E. 79 (2009) 26408.

[55] K.J. Daun, S.C. Huberman, Influence of particle curvature on transition regime heat conduction from aerosolized nanoparticles, Int. J. Heat Mass Transf. 55 (2012) 7668-7676.

[56] D.J. Rader, W.M. Trott, J.R. Torczynski, J.N.A. Castañeda, T.W. Grasser, Measurements of Thermal Accomodation Coefficients, 2005.

[57] M.L. Huber, A.H. Harvey, CRC Handbook of Chemistry and Physics, 92nd ed., CRC-Press, 2011.

[58] H.R. Maurer, H. Kersten, On the heating of nano- and microparticles in process plasmas, J. Phys. D. Appl. Phys. 44 (2011).

[59] H. Search, C. Journals, A. Contact, M. Iopscience, I.P. Address, Effects of Oxygen on the Properties of Sputtered Molybdenum Thin Films, Jpn. J. Appl. Phys. 30 (1991) 2069-2073.

[60] P. Patsalas, C. Charitidis, S. Logothetidis, The effect of substrate temperature and biasing on the mechanical properties and structure of sputtered titanium nitride thin films, Surf. Coatings Technol. 125 (2000) 335-340.

[61] S. Srivastava, J.P. Thomas, A. Rahman, M. Abd-ellah, M. Mohapatra, D. Pradhan, et al., Size-Selected $\mathrm{TiO} 2$ Nanocluster Catalysts for Efficient Photoelectrochemical Water Splitting, ACS Nano. 8 (2014) 11891-11898.

[62] M. Maicu, R. Schmittgens, D. Hecker, D. Glöß, P. Frach, G. Gerlach, et al., Synthesis and deposition of metal nanoparticles by gas condensation 
process, J. Vac. Sci. Technol. A. 32 (2014) 02B113.

[63] R.D. Boyd, I. Pilch, M. Garbrecht, M. Halvarsson, U. Helmersson, Double oxide shell layer formed on a metal nanoparticle as revealed by aberration corrected (scanning) transmission electron microscopy, Mater. Res. Express. 1 (2014) 25016.

[64] R.D. Boyd, R. Gunnarsson, I. Pilch, U. Helmersson, Characterisation of Nanoparticle Structure by High Resolution Electron Microscopy ., J. Phys. Conf. Ser. 522 (2014) 12065.

[65] A.M. Ahadi, O. Polonskyi, U. Schürmann, Stable production of TiOx nanoparticles with narrow size distribution by reactive pulsed dc magnetron sputtering, J. Phys. D. Appl. Phys. 48 (2015) 35501.

[66] J. Hanu, A. Choukourov, I. Melnichuk, H. Biederman, A. Serov, D. Slavínsk, Preparation of metal oxide nanoparticles by gas aggregation cluster source, Vacuum. 120 (2015) 162-169.

[67] A. Caillard, T. Lecas, P. Brault, A. Thomann, M.F. Barthe, C. Andrezza, et al., Synthesis of Ag, Pt and AgPt nanoparticles by magnetron based gas aggregation source, in: Poster at the 16th International Conference on Plasma Surface Engineering, 2016: p. 1009.

[68] E. Quesnel, V. Muffato, E. Quesnel, E. Pauliac-vaujour, V. Muffato, Modeling metallic nanoparticle synthesis in a magnetron-based nanocluster source by gas condensation of a sputtered vapor, J. Appl. Phys. 107 (2010) 54309.

[69] M.P. Saksena, S.C. Saxena, Thermal conductivity of mixtures of monoatomic gases, Proc. Natl. Inst. Sci. India Phys. Sci. (1963) 26.

[70] B. Vermang, J. Timo, V. Fjällström, F. Rostvall, M. Edoff, R. Gunnarsson, et al., Highly reflective rear surface passivation design for ultra-thin $\mathrm{Cu}$ ( In , Ga ) Se 2 solar cells, Thin Solid Films. 582 (2015) 300-303.

[71] J. Eriksson, D. Puglisi, C. Strandqvist, R. Gunnarsson, S. Ekeroth, I.G. Ivanov, et al., Modified Epitaxial Graphene on SiC for Extremely Sensitive and Selective Gas Sensors, in: Mater. Sci. Forum, 2016: pp. $1145-1148$.

[72] R. Zha, R. Nadimicherla, X. Guo, Morphology engineering of nanostructured TiO2 particles, RSC Adv. 5 (2015) 6481-6488.

[73] L. Yang, Y. Lin, J. Jia, X. Xiao, X. Li, X. Zhou, Light harvesting enhancement for dye-sensitized solar cells by novel anode containing cauliflower-like TiO 2 spheres, J. Power Sources. 182 (2008) 370-376. 


\section{Papers}

The papers associated with this thesis have been removed for copyright reasons. For more details about these see:

http:// urn.kb.se/ resolve?urn=urn:nbn:se:liu:diva-143843 